\title{
The cilium: a cellular antenna with an influence on obesity risk
}

\author{
Edwin C. M. Mariman ${ }^{1}$, Roel G. Vink ${ }^{1}$, Nadia J. T. Roumans ${ }^{1}$, Freek G. Bouwman ${ }^{1}$, \\ Constance T. R. M. Stumpel ${ }^{2,3}$, Erik E. J. G. Aller ${ }^{1}$, Marleen A. van Baak ${ }^{1}$ and Ping Wang ${ }^{2}$ \\ ${ }^{1}$ Department of Human Biology, School of Nutrition and Translational Research in Metabolism (NUTRIM), Maastricht \\ University Medical Centre, PO Box 616, 6200 MD Maastricht, The Netherlands \\ ${ }^{2}$ Department of Clinical Genetics, Maastricht University Medical Centre, PO Box 5800, 6202 AZ Maastricht, The Netherlands \\ ${ }^{3}$ School for Oncology \& Developmental Biology (GROW), Maastricht University Medical Centre, PO Box 5800,6202 AZ \\ Maastricht, The Netherlands
}

(Submitted 28 January 2016 - Final revision received 21 April 2016 - Accepted 2 May 2016 - First published online 20 June 2016)

\section{Abstract}

Primary cilia are organelles that are present on many different cell types, either transiently or permanently. They play a crucial role in receiving signals from the environment and passing these signals to other parts of the cell. In that way, they are involved in diverse processes such as adipocyte differentiation and olfactory sensation. Mutations in genes coding for ciliary proteins often have pleiotropic effects and lead to clinical conditions, ciliopathies, with multiple symptoms. In this study, we reviewed observations from ciliopathies with obesity as one of the symptoms. It shows that variation in cilia-related genes is itself not a major cause of obesity in the population but may be a part of the multifactorial aetiology of this complex condition. Both common polymorphisms and rare deleterious variants may contribute to the obesity risk. Genotype-phenotype relationships have been noticed. Among the ciliary genes, obesity differs with regard to severity and age of onset, which may relate to the influence of each gene on the balance between pro- and anti-adipogenic processes. Analysis of the function and location of the proteins encoded by these ciliary genes suggests that obesity is more linked to activities at the basal area of the cilium, including initiation of the intraflagellar transport, but less to the intraflagellar transport itself. Regarding the role of cilia, three possible mechanistic processes underlying obesity are described: adipogenesis, neuronal food intake regulation and food odour perception.

Key words: Obesity: Primary cilia: Adipocyte differentiation: Food odour sensation: Food intake regulation

Owing to its growing prevalence, obesity forms a global threat to public health and a burden to healthcare systems. Interventions by weight loss seem unable to bring this pandemic to a stop. Therefore, finding novel ways for treatment and prevention is a must, but depends on profound knowledge of the aetiology of obesity. Notably, the background of obesity is heterogeneous and complex, with involvement of genetic and environmental factors. Various physiological processes may be involved, including the response to environmental food cues, the hormonal regulation of hunger and satiety, the activity of the central reward system, whole-body energy expenditure and the storage capacity for fat in the adipose tissue. Each of these processes is related to the activity of a particular set of genes with some genes being involved in a broad spectrum of processes. Such genes are of special interest, because the pleiotropic effect of variation in those genes might explain a broader part of the aetiology of obesity. At the same time, those genes might be efficient targets for intervention.

Ciliary genes, which code for proteins required for the compartmentalised cilia biogenesis and function, represent such a group and have recently gained interest in the context of obesity. Cilia are specialised organelles extruding from eukaryotic cells (Fig. 1; more detailed information about the cilium structure and composition is available from the literature $)^{(1-7)}$, and are the product of a process that is referred to as ciliogenesis $^{(8)}$. There are two types of cilia, motile and immotile/ primary. Besides well-known motile cilia in the respiratory tract and the oviducts and immotile cilia of the inner ear and the nasal epithelium, almost every cell in the body carries a single primary cilium at a certain stage of its life cycle. Cilia regulate

Abbreviations: ADCY3, adenylate cyclase 3; ALMS1, Alström syndrome protein 1; ANKRD26, ankyrin repeat domain 26; ARL6, ADP-ribosylation factor-like 6; AURKA, aurora kinase A; BBS, Bardet-Biedl syndrome; BTC, basal transport complex; CCT, chaperonin containing TCP1; HDAC6, histone deacetylase 6; IFT, intraflagellar transport; IGF1-R, insulin-like growth factor 1 receptor; INPP5E, inositol polyphosphate-5-phosphatase E; KIF3A, kinesin family member 3A; NPHP, nephronophthisis; OR, olfactory receptor; PCM1, pericentriolar material 1; PDE6D, phosphodiesterase 6D; PI(4,5)P2, phosphatidylinositol (4,5)diphosphate; POMC, pro-opiomelanocortin; PTHB1, parathyroid hormone responsive B1; RABL4, RAB-like 4; RPGRIP1L, retinitis pigmentosa GTPase regulator interacting protein 1-like; SDCCAG8, serologically defined colon cancer antigen 8; SHH, sonic hedgehog; TCTN1-3, tectonic family member 1-3; TTC21B, tetratricopeptide repeat domain 21B; WDPCP, WD repeat containing planar cell polarity effector; WDR10, WD repeat domain 10.

*Corresponding author: E. C. M. Mariman, email e.mariman@maastrichtuniversity.nl 


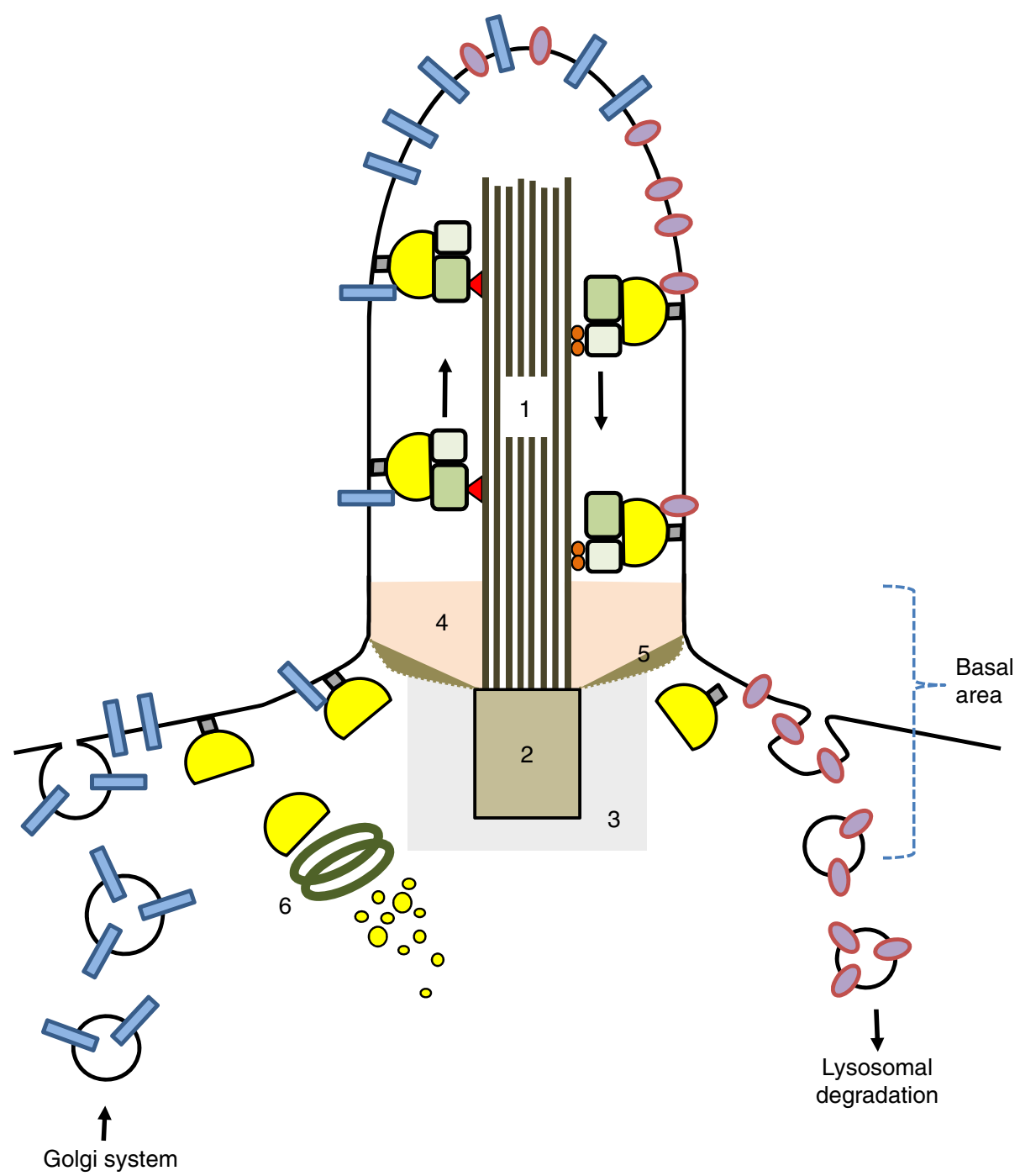

Fig. 1. Schematic representation of the cilium and the intraflagellar transport. 1, Axoneme; 2 , basal body; 3 , pericentriolar satellite; 4 , transition zone; 5 , transition fibre; 6, assembly complex; \0, membrane receptors; ○, structural Bardet-Biedl syndrome (BBS) proteins; $\bigcirc$, BBSome; $\square$, BBS3; $\square$, intraflagellar transport (IFT)-A; $\square$, IFT-B; $\triangleleft$, kinesin; 8, dynein.

the proper differentiation and migration of all kinds of cells in the body, are involved in signal transduction and allow cells to obtain environmental information as part of sensory systems $^{(9-13)}$. Mutations in ciliary genes can cause monogenic disorders referred to as ciliopathies with pleiotropic consequences for the phenotype, which can include obesity. In this study, we focus on the obesity-linked subset of ciliary genes, review the clinical presentation of mutations, location of the ciliary proteins in the cell and their most likely function, and describe mechanisms by which they might contribute to the genetic background of obesity. In addition, we present our own experimental data of those genes in recent obesity and weight-loss studies.

\section{Clinical presentation of obesity-linked ciliary genes}

Because of the multiplicity of cilia functions, ciliopathy patients usually suffer from a range of symptoms and their condition is often classified as a syndrome. Examples of such conditions are the autosomal recessive Bardet-Biedl syndrome (BBS; MIM209900) and Alström syndrome (MIM203800). Among patients with different clinical entities due to a different mutated gene, symptoms may overlap ${ }^{(14)}$. For instance, BBS patients can present with retinitis pigmentosa, truncal obesity, renal dysfunction, polydactyly, behavioural dysfunction and hypogonadism as major symptoms, but also with diabetes, hepatic complaints and olfactory and/or auditory deficiencies. Alström syndrome is characterised by blindness, hearing loss, childhood obesity with hyperinsulinaemia and type 2 diabetes mellitus, but also by cardiomyopathy and by renal, pulmonary and/or hepatic dysfunction. Although mutations in different genes may cause similar symptoms, it is also possible that different mutations in the same ciliary gene lead to different clinical diagnoses. For instance, patients with mutations in the Meckel syndrome type 1 (MKS1) gene can present with BBS or Meckel-Gruber syndrome, whereas various mutations in CEP290 may lead to BBS, Joubert or Meckel syndrome as well as Leber congenital amaurosis ${ }^{(15)}$. 
Some ciliopathy syndromes are genetically heterogeneous such as BBS, for which nineteen genes have already been reported $^{(16)}$. For other ciliopathy syndromes, only a single gene has been identified, as is the case for Alström syndrome. Other single-gene, obesity-linked ciliopathies are a syndrome with mental retardation, truncal obesity, retinal dystrophy and micropenis (MIM610156) ${ }^{(17,18)}$ and a syndrome with morbid obesity and spermatogenic failure (morbid obesity syndrome 1 or morbid obesity and spermatogenic failure syndrome, MIM615703). The latter is a condition with morbid obesity in humans, and in the mouse presents with obesity, hyperphagia and insulin resistance ${ }^{(19)}$.

A patient is diagnosed with BBS when at least four of the following six major manifestations are scored: retinopathy, obesity, polydactyly, genital abnormalities, cognitive impairment and renal anomalies. It means that BBS patients do not necessarily have to be obese. In Table 1, we have listed various clinical conditions based on mutations in ciliary genes, and we have indicated for which of those genes obesity has actually been reported. It shows that for two of the BBS genes, BBS11 and BBS15, obesity has not been reported as a symptom among patients. Interestingly, Bbs11/ Trim32-knockout mice also do not become obese, although adult male mice have a $10 \%$ increased body weight originating from the non-muscle mass ${ }^{(77)}$. When a mutated ciliary gene leads to Joubert syndrome, obesity is commonly not part of the symptoms. However, recently, a patient with Joubert syndrome and obesity has been reported with a homozygous missense mutation in the $A R L 13 B$ gene, which affects ciliogenesis ${ }^{(21)}$.

Besides clinical presentation, animal studies may also reveal new interesting genes in this cilia-obesity context. Recently, it was shown that knocking out the ankyrin repeat domain 26 (Ankrd26) gene in the mouse leads to defects of primary cilia in regions of the central nervous system, accompanied by hyperphagia, obesity and gigantism ${ }^{(78)}$. The human $A N K R D 26$ gene is situated in a locus for obesity on chromosome 10p with a maternal parent-of-origin effect ${ }^{(79)}$. However, mutations in this gene have not yet been described in connection to obesity in humans. Another gene of which mutations lead to symptoms including obesity in the mouse is $T u b^{(80)}$. The protein of this gene is probably involved in the selective import of $G$ proteincoupled receptors into cilia $^{(81)}$.

\section{Functions of obesity-linked ciliary proteins and their closely interacting partners}

\section{The BBSome}

The elucidation of the underlying genes in BBS led to the discovery of a special protein complex, the BBSome ${ }^{(82)}$. The function of the BBSome includes, but may not be limited to, the intraciliary (intraflagellar) trafficking of a diverse set of molecules (Fig. 1). This includes membrane-embedded receptors for signal transduction as well as structural components of the cilium. As such, the BBSome is important for the establishment, growth, turnover and functioning of cilia $^{(83,84)}$. BBS1, BBS2, BBS4, BBS5, BBS7, BBS8 and BBS9 are part of the BBSome together with the $10 \mathrm{kDa}$ BBSome interacting protein 1 (BBIP1), also referred to as BBIP10 or BBS18 $8^{(44,85)}$.

\section{Chaperonin activity}

Not all BBS genes code for components of the BBSome; three of the BBS genes code for chaperonin-like proteins: BBS3, BBS10 and BBS12. They share sequence homology with genes coding for members of the chaperonin containing TCP1 (CCT)/TCP1 ring complex (TRiC) family of chaperonins, which take part in ATP-dependent protein folding. The three BBSome proteins associate with six CCT-chaperonins, CCT1, CCT2, CCT3, CCT4, CCT5 and ССT8, to form a complex that is involved in the assembly of the BBSome ${ }^{(86)}$. The assembly starts with the interaction of BBS2 with BBS7 and BBS9, forming a core particle to which the other structural BBS proteins attach ${ }^{(87)}$. BBS18 appears to be important for enabling the incorporation of BBS4 into the BBSome $^{(88)}$. It was observed that BBS2 is subject to ubiquitination. Therefore, turnover of BBS2 via the ubiquitin-proteasome pathway might be important for the regulation of BBSome quantity. BBS11/tripartite motif containing 32 (TRIM32), which has been shown to be an E3 ubiquitin ligase for actin and dysbindin, was suggested to be the processor of $\mathrm{BBS}^{(87)}$.

\section{Intraflagellar transport}

To enable intraflagellar transport (IFT), two other protein complexes are needed, IFT-A and IFT-B. The IFT-A particle is composed of IFT43 (c14orf179), IFT121 (WDR35), IFT122 (WD repeat domain 10; WDR10), IFT139, IFT140 (uncharacterized KIAA gene 0590; KIAA0590) and IFT144 (WDR19) ${ }^{(89)}$, whereas the B-particle is composed of IFT20, IFT25, IFT27, IFT46, IFT52, IFT57, IFT72, IFT74, IFT80, IFT81, IFT88 and IFT172 (selective LIM-binding factor; SLB) ${ }^{(60)}$. Mediated by IFT144, the BBSome can interact with the IFT-A and IFT-B particles to form the basal transport complex (BTC), which moves along the central axoneme (Fig. 1). Membrane-embedded receptor proteins at the base of the cilium can dock to the BTC, and are then transported to the tip of the cilium. Although much of what we know about the function of these proteins has been collected from studies on Chlamydomonas and Caenorbabditis elegans, a similar model seems to be operative in mammalian cilia $^{(84)}$.

In a more advanced model, the IFT-B particle in connection with kinesins such as kinesin II and its component kinesin family member 3A (KIF3A) ${ }^{(90)}$ drives the anterograde transport of proteins to the tip of the cilium, from which the IFT-A particle in connection with dyneins drives the retrograde transport ${ }^{(91)}$. Observations in the Ift27-knockout mouse indicate that IFT27, a component of the IFT-B particle, together with BBS17/leucine zipper transcription factor-like 1 (LZTFL1), facilitates the retrograde transport of BBS proteins and sonic hedgehog ( $\mathrm{SHH}$ ) receptors from the cilium ${ }^{(92)}$. In vitro, Liew et al. ${ }^{(93)}$ found that IFT27 can bind to unloaded BBS3/ADP-ribosylation factor-like 6 (ARL6). BBS3/ARL6, after being loaded with GTP, is assumed to link the BBSome to the membrane ${ }^{(94,95)}$. What may happen is that, when the BTC reaches the top of the cilium, BBS3/ARL6bound GTP is hydrolysed, perhaps by the action of the Rab-like GTPase IFT27, and as a consequence BBSomes are released from the membrane. Next, the release of IFT27 allows the activation of BBS3/ARL6 by GTP binding and attachment of 
Table 1. Clinical syndromes due to mutations in ciliary genes

\begin{tabular}{|c|c|c|c|c|}
\hline Disorders & MIM & Gene names & Obesity reported & References \\
\hline Alström syndrome & 203800 & ALMS1 & Yes & (20) \\
\hline Joubert Syndrome 8 & 612291 & ARL13B & Yes & (21) \\
\hline Meckel Syndrome 9 & 614209 & B9D1 & No & (22) \\
\hline Bardet-Biedl Syndrome 1 & 209900 & BBS1 & Yes & $(15,23-25)$ \\
\hline Bardet-Biedl Syndrome 2 & 615981 & BBS2 & Yes & $(23,25,26)$ \\
\hline Bardet-Biedl Syndrome 3 & 600151 & BBS3/ARL6 & Yes & (27) \\
\hline Bardet-Biedl Syndrome 4 & 600374 & BBS4 & Yes & $(23,25,28)$ \\
\hline Bardet-Biedl Syndrome 5 & 615983 & BBS5 & Yes & $(23,29)$ \\
\hline Bardet-Biedl Syndrome 6 & 605231 & BBS6/MKKS & Yes & $(25,30)$ \\
\hline Bardet-Biedl Syndrome 7 & 615984 & BBS7 & Yes & (23) \\
\hline Bardet-Biedl Syndrome 8 & 608132 & BBS8/TTC8 & Yes & $(23-25)$ \\
\hline Bardet-Biedl Syndrome 9 & 615986 & BBS9/PTHB1 & Yes & (31) \\
\hline Bardet-Biedl Syndrome 10 & 615987 & BBS10 & Yes & $(15,23,25,32)$ \\
\hline Bardet-Biedl Syndrome 11 & 615988 & BBS11/TRIM32 & No & (33) \\
\hline Limb-girdle muscular dystrophy $2 \mathrm{H}$ & 254110 & Id. & No & (34) \\
\hline Bardet-Biedl Syndrome 12 & 615989 & BBS12 & Yes & $(23)$ \\
\hline Bardet-Biedl Syndrome 13 & 615990 & BBS13/MKS1 & Yes & $(15,35)$ \\
\hline Meckel Syndrome 1 & 249000 & Id. & No & (36) \\
\hline Bardet-Biedl Syndrome 14 & 615991 & BBS14/CEP290/NPHP6 & Yes & (15) \\
\hline Leber congenital amaurosis & 611755 & Id. & No & (37) \\
\hline Joubert Syndrome 5 & 610188 & Id. & No & (38) \\
\hline Meckel Syndrome 4 & 611134 & Id. & No & (39) \\
\hline Bardet-Biedl Syndrome 15 & 615992 & BBS15/WDPCP & No & $(40)$ \\
\hline Bardet-Biedl Syndrome 16 & 615993 & BBS16/SDCCAG8 & Yes & $(41,42)$ \\
\hline Senior-Loken Syndrome 7 & 613615 & Id. & No & (23) \\
\hline Bardet-Biedl Syndrome 17 & 615994 & BBS17/LZTFL1 & Yes & $(43)$ \\
\hline Bardet-Biedl Syndrome 18 & 613605 & BBS18/BBIP1/BBIP10 & Yes & $(44)$ \\
\hline Bardet-Biedl Syndrome 19 & 615996 & BBS19/IFT27/RABL4 & Yes & $(45)$ \\
\hline Meckel Syndrome 6 & 612284 & CC2D2A & No & $(46)$ \\
\hline Joubert Syndrome 9 & 612285 & Id. & No & $(47)$ \\
\hline $\mathrm{COACH}$ Syndrome & 216360 & Id. & No & $(47)$ \\
\hline Neuropathy, hereditary sensory, with spastic paraplegia & 256840 & CCT5 & No & $(48)$ \\
\hline MOSPGF syndrome & 615703 & CEP19 & Yes & $(19)$ \\
\hline Sensenbrenner syndrome (CED3) & 614099 & IFT43/C14ORF179 & No & $(49)$ \\
\hline Short-rib thoracic dysplasia 2 & 611177 & IFT80/WDR56 & No & $(50)$ \\
\hline Meckel Syndrome-like & - & IFT88 & No & $(51)$ \\
\hline Sessenbrenner syndrome (CED2) & 613610 & IFT121/WDR35 & No & $(49)$ \\
\hline Sensenbrenner syndrome (CED1) & 218330 & IFT122/WDR10 & No & $(52)$ \\
\hline Nephronophthisis 12 & 613820 & IFT139/TTC21B & No & $(53,54)$ \\
\hline Mainzer-Saldino syndrome & 266920 & IFT140/KIAA0590 & No & (55) \\
\hline Short-rib thoracic dysplasia 9 & 266920 & Id. & No & $(56)$ \\
\hline Nephronophthisis 13 & 614377 & IFT144/WDR19 & No & $(57)$ \\
\hline Retinitis pigmentosa 71 & 616394 & IFT172 & Yes & $(58)$ \\
\hline Growth hormone deficiency & - & Id. & Yes & $(59)$ \\
\hline Mainzer-Saldino syndrome & 615630 & Id. & Yes & $(60)$ \\
\hline MORM syndrome & 610156 & INPP5E & Yes & $(17,18)$ \\
\hline Joubert Syndrome 1 & 213300 & Id. & No & $(61)$ \\
\hline Nephronophthisis 1 & 256100 & NPHP1 & No & (62) \\
\hline Joubert Syndrome 4 & 609583 & Id. & No & (63) \\
\hline Senior-Loken Syndrome 1 & 266900 & Id. & No & (64) \\
\hline Nephronophthisis 4 & 606966 & NPHP4 & No & (65) \\
\hline Senior-Loken Syndrome 4 & 606966 & Id. & No & $(65)$ \\
\hline Joubert Syndrome 22 & 615665 & PDE6D & No & (66) \\
\hline Meckel Syndrome 5 & 611561 & RPGRIP1L & No & $(67)$ \\
\hline COACH Syndrome & 216360 & Id. & No & $(68)$ \\
\hline Joubert Syndrome 7 & 611560 & Id. & No & $(67,69)$ \\
\hline Joubert Syndrome 13 & 614173 & TCTN1 & No & (2) \\
\hline Meckel Syndrome 8 & 613885 & TCTN2 & No & (70) \\
\hline Joubert Syndrome 24 & 616654 & Id. & No & (4) \\
\hline Meckel Syndrome 3 & 610688 & TMEM67 & No & (71) \\
\hline Joubert Syndrome 6 & 607361 & Id. & No & (72) \\
\hline $\mathrm{COACH}$ Syndrome & 216360 & Id. & No & (68) \\
\hline Nephronophthisis 11 & 613550 & Id. & No & (73) \\
\hline Meckel Syndrome 2 & 603194 & TMEM216 & No & $(74)$ \\
\hline Joubert Syndrome 2 & 608091 & Id. & No & $(74,75)$ \\
\hline Joubert Syndrome 14 & 614424 & TMEM237 & No & $(76)$ \\
\hline
\end{tabular}

Id., idem; $\mathrm{COACH}$, cerebellar vermis defect, oligophrenia, ataxia, coloboma, hepatic fibrosis; MOSPFG, morbid obesity and spermatogenic failure; MORM, mental retardation, truncal obesity, retinal dystrophy and micropenis. For expansions of gene names, see the text or the abbreviations list. 
BBSomes to the membrane, in order to start the export of cargo proteins such as $\mathrm{SHH}$ receptors from the cilium ${ }^{(93)}$. Studies in the mouse and in zebrafish have suggested that another protein, clusterin associated protein 1 (CLUAP1), is also associated with IFT, possibly as part of the IFT-B particle, and may be involved in regulating the transport at the base and tip of the cilia ${ }^{(96,97)}$. The knockout mouse of this gene has a severe phenotype and dies at embryonic mid-gestation ${ }^{(96)}$

\section{The basal area of the cilium}

On the basal area of the cilium, three substructures can be distinguished: the basal body with transition fibres, the transition zone and the pericentriolar satellite. It is the area where many BBS proteins are active, and where the BBSome is assembled and the cargo proteins are uploaded or unloaded; two obesity-linked ciliary proteins, Alström syndrome protein 1 (ALMS1) and centrosomal protein $19 \mathrm{kDa}$ (CEP19), are located at the basal body of the cilium and the subdistal centriolar appendage (transition fibre), respectively ${ }^{(19,98-100)}$. Absence of Alms1 in the mouse leads to changes in shape and orientation of cilia in hair cells ${ }^{(100)}$. Disruption of Alms1 in drosophila induces over-activation of the Notch signalling pathway, similar to after disruption of BBS1, BBS3 or BBS4, with the accumulation of Notch receptors in endosomes ${ }^{(101)}$. This observation suggests that ALMS1 and BBS proteins are involved in endosomal cycling and breakdown of signal transduction receptors occurring at the base of the cilium.

The transition zone is a region that forms the border between the cilium and the cell and prevents the free exchange of proteins between the cilium membrane and the plasma membrane ${ }^{(42)}$. Several proteins have been localised to this area, such as BBS13, BBS14, BBS15 and BBS16. In addition, particular complexes have been identified in this region such as the TCTN complex, which contains tectonic family member 1-3 (TCTN1-3), B9 protein domain 1 (B9D1), BBS13, BBS14, coiledcoil and C2 domain containing 2A (CC2D2A), transmembrane protein 67 (TMEM67) and TMEM216, and the HPNP complex composed of HPNP1, 4, 8 and retinitis pigmentosa GTPase regulator interacting protein 1 -like $(\text { RPGRIP1L) })^{(2,4,76,102)}$. It is suggested that they may function as gatekeepers for proteins that, being linked to the BBSome, are to be transported into and out of the cilium.

Investigations in embryos of knockout mice suggest that Rpgrip11, which is located at the transition zone, in interaction with proteasome $26 \mathrm{~S}$ subunit, non-ATPase 2 (Psmd2) regulates proteasome activity at the basal body of the cilium ${ }^{(103)}$. Although in humans no mutation in the RPGRIP1L gene has been reported in connection to obesity, the heterozygotes of the Rpgrip1l-knockout mouse are hyperphagic, have more fat mass and have a reduced suppression of food intake in response to leptin. In the hypothalamus of the heterozygous mice, the number of adenylate cyclase 3 (ADCY3)-positive cilia is decreased, with impaired localisation of the leptin receptor near the cilia, and reduced leptin signalling. A similar phenotype was observed in human fibroblasts with hypomorphic mutations in RPGRIP1L $\mathrm{L}^{(104)}$
The BBSome may transiently interact with PCM-1, a major protein of the pericentriolar satellite. Through BBS1, the BBSome interacts with RAB interacting protein 8 (RABIN8), the RAS oncogene family member 8 (RAB8) nucleotide exchange factor. It stimulates GTP binding to RAB8, which in turn directs vesicles to the cilium for ciliary membrane elongation ${ }^{(82,105)}$.

\section{Inositol transduction and cyclic AMP signalling}

The obesity-linked enzyme inositol polyphosphate-5-phosphatase E (INPP5E) has a function in inositol metabolism, hydrolysing phosphatidylinositol $(4,5)$-diphosphate $(\mathrm{PI}(4,5) \mathrm{P} 2)$ and phosphatidylinositol $(3,4,5)$-triphosphate $(\mathrm{PI}(3,4,5) \mathrm{P} 3)$, and as such is an important mediator of inositol signal transduction ${ }^{(106)}$. In addition, INPP5E activity regulates the phosphoinositide composition of the cilium membrane, which may have an influence on ciliary protein trafficking ${ }^{(107-109)}$. In the mouse, Inpp5e has been spotted in the axoneme ${ }^{(18)}$. Targeting of INPP5E into the cilium requires farnesylation and interaction with phosphodiesterase $6 \mathrm{D}^{(66,110)}$. Inactivation of INPP5E was shown to lead to cilium instability, which can be restored by blocking phosphoinositide 3 -kinase $(\mathrm{PI} 3 \mathrm{~K})^{(18)}$. Inactivation results in the accumulation of $\mathrm{PI}(4,5) \mathrm{P} 2$ at the tip of the cilium and in depletion of phosphatidylinsositol 4-phosphate (PI4P). It attracts PI(4,5)P2associated proteins such as Tubby-related protein (Tulp) and $G$ protein-coupled receptor 161 (Gpr161), which induce changes in cyclic AMP (cAMP) production and Shh signalling ${ }^{(107,108)}$.

Interaction of INPP5E with phosphodiesterase 6D indicates a link between inositol transduction and turnover of the second messenger cAMP. In fact, cilia contain various adenylate cyclases, of which type III (ADCY3) is relatively abundant. Links between the $A D C Y 3$ gene and obesity have been reported both in humans and in mice. In a Swedish cohort, genetic association was found between variants of the ADCY3 gene and men with obesity and type 2 diabetes ${ }^{(111)}$. In the Han population, genetic association with obesity was also observed ${ }^{(112)}$. Adcy3-knockout mice present with obesity, hyperphagia, low locomotor activity and leptin insensitivity ${ }^{(113)}$. Such mice also demonstrate anosmia towards IP3-and cAMP-generating odourants ${ }^{(114)}$, which is not surprising, as olfaction depends on sensory cilia with a functional $A D C Y 3$ gene.

\section{Cilium stability}

It has been observed that BBS18 is involved in microtubule stabilisation, for which its interaction with histone deacetylase 6 (HDAC6) is of importance ${ }^{(88,115)}$. HDAC6 deacetylates $\alpha$-tubulin, and thereby de-stabilises the cilium ${ }^{(88,115)}$. It is activated by aurora kinase A (AURKA), which co-localises at the base of the cilium with neural precursor cell expressed, developmentally down-regulated 9 (NEDD9)/human enhancer of filamentation 1 (HEF1), a factor involved in the cilia-related cancer disorder von Hippel-Lindau syndrome ${ }^{(116)}$. In fact, the phosphorylation of HDAC6 depends on the interaction of AURKA with NEDD9 ${ }^{(117)}$. Interestingly, INPP5E can also be activated by AURKA, which in turn down-regulates transcription of the AURKA gene ${ }^{(118)}$. Although activation of HDAC6 destabilises the cilium ${ }^{(88,115)}$, activation of INPP5E has a stabilising effect ${ }^{(18)}$. In this regard, 
Table 2. Location and function of ciliary proteins

\begin{tabular}{|c|c|c|}
\hline Genes & Cellular localisation and function & References \\
\hline ALMS1* & Localises to the basal body of cilia & $(99,120)$ \\
\hline ARL13B* & Required for ciliogenesis & $(21,121)$ \\
\hline B9D1 & Transition zone; basal body & $(2,76,102)$ \\
\hline BBS1* & Structural component of the BBSome, required for incorporation of BBS4 & (87) \\
\hline BBS2* $^{*}$ & Structural component of the BBSome & (87) \\
\hline BBS3/ARL6* & BBSome assembly, binding of the BBSome to the membrane & (93) \\
\hline $\mathrm{BBS}^{*}$ & Final incorporated structural component of the BBSome, located at pericentriolar satellite (interacts with PCM1) & (87) \\
\hline BBS5* & Structural component of the BBSome & (87) \\
\hline BBS6/MKKS* & BBSome assembly & (87) \\
\hline $\mathrm{BBS7}^{*}$ & Structural component of the BBSome & (87) \\
\hline BBS8/TTC8* & Structural component of the BBSome & (87) \\
\hline BBS9/PTHB1* & Structural component of the BBSome & $(87)$ \\
\hline BBS10* & BBSome assembly & (87) \\
\hline BBS11/TRIM32 & Proposed E3 ubiquitin ligase for BBS2 in the assembly of the BBSome & (87) \\
\hline${\mathrm{BBS} 12^{*}}^{*}$ & BBSome assembly & (87) \\
\hline BBS13/MKS1* & Part of the tectonic-like complex (transition zone complex); basal body & $(2,4)$ \\
\hline BBS14/CEP290/NPHP6* & Part of the tectonic-like complex (transition zone complex); centriolar satellite; basal body & $(2,4)$ \\
\hline BBS15/WDPCP & Present in the transition zone & (122) \\
\hline BBS16/SDCCAG8* & Localises in the transition zone, present in the pericentriolar satellite (interacts with PCM1) & (23) \\
\hline BBS17/LZTFL1* & Retrograde transport of $\mathrm{SHH}$ receptors & (123) \\
\hline BBS18/BBIP1/BBIP10* & (de)Stabilisation of cilia by regulating de-acetylation of tubulin, BBS4-incorporation into the BBSome & $(88,115)$ \\
\hline BBS19/IFT27/RABL4* & Component of the IFT-B particle, plays a role in BBS3 activation during retrograde transport & (93) \\
\hline CC2D2A & Transition zone; basal body & $(4,102)$ \\
\hline CEP19* & Transition fibre & (98) \\
\hline IFT88 & Component of the IFT-B particle & (60) \\
\hline IFT172* & Component of the IFT-B particle & (124) \\
\hline INPP5E* & Located in the axoneme, regulated by AURKA, CAMP and SHH regulation via inositol pathway & $(18,107,118)$ \\
\hline NPHP1 & Transition zone & $(4,102)$ \\
\hline NPHP4 & Transition zone & $(2,4,102)$ \\
\hline RPGRIP1L* & Transition zone; basal body & $(2,103)$ \\
\hline TCTN1 & Transition zone, component of the tectonic-like complex & (2) \\
\hline TCTN2 & Transition zone, component of the tectonic-like complex; axoneme; basal body & $(2,4)$ \\
\hline TMEM67 & Transition zone; axoneme & $(2,102)$ \\
\hline TMEM216 & Transition zone; axoneme; basal body & $(2,76)$ \\
\hline TMEM237 & Transition zone & (76) \\
\hline
\end{tabular}

$\mathrm{SHH}$, sonic hedgehog; IFT, intraflagellar transport; AURKA, aurora kinase A; cAMP, cyclic AMP. For expansions of gene names, see the text or the abbreviations list. * Mutation in the gene associated with obesity in human and/or mouse.

AURKA may play a key role in cilium turnover, and as such in the risk for obesity ${ }^{(88,107,115,118)}$.

\section{Pinpointing obesity to the basal area of the cilium}

Mutations disrupting the function of the structural BBS proteins are supposed to hamper IFT, giving rise to obesity. As the IFT particles are associated with the BBSome, one would expect that mutations in the IFT proteins would also often lead to obesity. However, as can be seen in Table 1, this is only the case for BBS19/IFT27 and IFT172. The lack of obesity might be explained by a more severe phenotype of mutations, leading to prenatal or early postnatal death. Skeletal and renal abnormalities are common, in line with the function of primary cilia in those tissues ${ }^{(119)}$. It is also possible that with modern efficient sequencing methods, mutations in milder phenotypes of obesity are expected to be detected more often in the coming time. Alternatively, obesity is not so much a consequence of ciliary transport itself. As Table 2 shows, many of the obesitylinked ciliary proteins are located at the basal area of the cilium. In this region, the assembly of the BBSome takes place, its attachment to the membrane and its loading with the proper cargo protein. It is therefore tempting to speculate that obesity results from an altered initiation of the ciliary transport at the basal area of the cilium.

\section{Genetic studies regarding obesity-linked ciliary genes}

BBS is associated with truncal obesity. Compared with BMI-matched controls, BBS patients have a similar energy metabolism with higher visceral fat mass and higher leptin levels ${ }^{(125)}$. Apparently, these higher values are related to the underlying genetic defect ${ }^{(126)}$. BBS1 is for $80 \%$ caused by the M390R missense mutation and patients show diet-responsive obesity $^{(127)}$. For this mutation, a knock-in mouse has been generated $^{(128)}$. The homozygous mice are obese, hyperphagic, have increased leptin levels and reduced locomotor activity. It proves that obesity is indeed a consequence of this gene mutation. Ultrastructural examination showed elongated cilia and swollen distal ends, but an intact axonemal structure ${ }^{(128)}$. Notably, phenotypic differences occur between the BBS subtypes. BBS10 patients have a significantly higher visceral fat mass than BBS1 patients ${ }^{(125)}$. Differences have also been observed with regard to the severity and age-of-onset of obesity. Comparing BBS2 patients and BBS4 patients, Carmi et $a{ }^{(129)}$ found that for BBS2 obesity was relatively mild, 
whereas BBS4 was associated with early-onset morbid obesity. Further, genetic variants of BBS genes were found to be associated with different types of common obesity. In a study among French-Caucasian individuals ${ }^{(130)}$, the association was found between BBS2 (rs4784675) and common adult obesity, between BBS4 (rs7178130) and BBS6 (rs6108572) and earlyonset childhood obesity, and between BBS6 (rs221667) and adult severe obesity. Other studies did not show genetic associations. Variation in the BBS6 gene among Danish obese subjects did not show significant association with common types of obesity ${ }^{(131)}$. Studying SNP for fourteen BBS genes in large cohorts of women did not show association with body weight or body fat, suggesting that common variation in BBS genes does not have a significant influence on body weight and $\mathrm{fat}^{(132)}$. This is in line with the outcome of a segregation analysis from 1995 by Reed et al. ${ }^{(133)}$ in 207 sibling pairs, showing that BBS genes do not co-segregate with extreme obesity. Possibly, the penetrance of BBS gene mutations with regard to obesity is limited and/or the contribution to obesity risk depends more on rare alleles.

Previously, we sequenced thirty subjects with extreme obesity $^{(134,135)}$. We checked for relatively rare variants (frequency $<0 \cdot 01$ ) with a predicted damaging impact on protein function in sixty-six genes that code for proteins, which are needed for proper cilia function (online Supplementary Table S1), including the genes mentioned in Tables 1 and 2.
This resulted in the identification of twenty-four variants in seventeen subjects (Table 3). The BBS5 N184S variant in subject 628 represents a serine substitution of an asparagine residue that is highly conserved within the two DM16 domains of the protein $^{(29,136)}$; this has been reported before in two families with BBS5 ${ }^{(136)}$. However, the two heterozygous patients of one of those families were also homozygous for the common M390R mutation in BBS1. Therefore, it was suggested that BBS5 interacts with BBS1 and that the N184S variant acts a modifier of the BBS phenotype. Besides these rare variants, we observed a non-synonymous SNP in BBS1O (rs35676114, P539L) with a minor allele frequency of $0 \cdot 07$. For this SNP, we found association with extreme obesity in the examined cohort $\left(\chi^{2}, P=0 \cdot 0004\right)$.

All subjects were heterozygous for the rare altered allele in line with the absence of syndromic symptoms. On the other hand, heterozygous variants may contribute to the phenotype as reported by McEwen et al. ${ }^{(37)}$, who found reduction of smell perception in homozygotes and heterozygotes of the Cys998X mutation in CEP290. In this respect, the observed heterozygous variants might exert a small phenotypic effect. An accumulation of small effects from various rare alleles would fit with a multifactorial genetic background. Notably, subject 869 carried marked variations in four genes: BBS1, IFT46, IFT88 and $A N K R D 26$. Indeed, our observation shows the presence of a considerable number of rare alleles with a predicted

Table 3. Exome sequencing results of rare variants with a predicted impact on protein function in extremely obese subjects

\begin{tabular}{|c|c|c|c|c|c|c|c|c|c|}
\hline \multirow[b]{2}{*}{ Genes } & \multirow[b]{2}{*}{$\begin{array}{l}\text { Person } \\
\text { ID }\end{array}$} & \multirow[b]{2}{*}{ rs-number } & \multirow[b]{2}{*}{$\begin{array}{l}\text { Nucleotide } \\
\text { change }\end{array}$} & \multirow[b]{2}{*}{$\begin{array}{l}\text { Amino acid } \\
\text { change }\end{array}$} & \multicolumn{4}{|c|}{ Functional prediction (reference) } & \multirow{2}{*}{$\begin{array}{l}\text { Population } \\
\text { Frequency }\end{array}$} \\
\hline & & & & & SIFT† & PolyPhen2 & $\begin{array}{c}\text { Mutation } \\
\text { taster }\end{array}$ & $\begin{array}{c}\text { LRT } \\
\text { prediction }\end{array}$ & \\
\hline ADCY3‡ & 659 & - & Gta/Ata & V860I & 0.41 & B & D & D & No \\
\hline \multirow[t]{2}{*}{ ANKRD26 } & 869 & 139049098 & $\mathrm{caC} / \mathrm{caG}$ & $\mathrm{H} 51 \mathrm{Q}$ & 0.01 & $\mathrm{D}$ & $\mathrm{N}$ & ND & $0.0002 \S$ \\
\hline & 633 & 191015656 & $\mathrm{aCa} / \mathrm{aTa}$ & T181I & 0.00 & D & $\mathrm{N}$ & ND & $0.001 \|$ \\
\hline BBS1‡ & 869 & - & $c G a / c A a$ & R440Q & 0.01 & D & ND & ND & No" \\
\hline BBS5 $\ddagger$ & 628 & 137853921 & aAt/aGt & N184S & 0.00 & $\mathrm{D}$ & $\mathrm{D}$ & $\mathrm{D}$ & $0.009 \|$ \\
\hline BBS8(TTC8)‡ & 698 & 140698625 & $\mathrm{Cgg} / \mathrm{Tgg}$ & R459W & 0.00 & D & D & $\mathrm{N}$ & $0.001 \S$ \\
\hline \multirow[t]{2}{*}{ BBS9 } & 588 & - & $\mathrm{tG} / / \mathrm{tTt}$ & $\mathrm{C} 104 \mathrm{~F}$ & ND & $\mathrm{P}$ & $\mathrm{D}$ & $\mathrm{D}$ & No \\
\hline & 692 & 59252892 & $\mathrm{aCt} / \mathrm{aTt}$ & T549I & ND & $\mathrm{P}$ & D & D & $0.003 \S$ \\
\hline BBS11(TRIM32)‡ & 593 & 117599771 & $\mathrm{caG} / \mathrm{caC}$ & Q186H & ND & $\mathrm{P}$ & D & D & $0.006 \|$ \\
\hline BBS14(CEP290)‡ & 968 & - & Gct/Act & A76T & 0.52 & D & $\mathrm{N}$ & D & 0.001 \\
\hline \multirow[t]{2}{*}{ CC2D2A } & $852 / 1003$ & 144439937 & Aag/Gag & K507E & 0.29 & D & $\mathrm{N}$ & D & $0.009 \|$ \\
\hline & 709 & - & $c G c / c A c$ & $\mathrm{R} 1618 \mathrm{H}$ & 0.02 & $\mathrm{D}$ & $\mathrm{D}$ & $\mathrm{D}$ & $0.00003 \S$ \\
\hline CCT5 & 659 & 141675330 & atC/atG & I362M & 0.12 & B & D & D & $0.002 \|$ \\
\hline CCT7 & 646 & 200915592 & Ggc/Agc & G377S & 0.06 & D & D & D & $0.0006 \S$ \\
\hline IFT121(WDR35) & 852 & 138202017 & Ggg/Agg & G93R & 0.31 & D & D & D & $0.0002 \S$ \\
\hline IFT144(WDR19) & $588 / 612$ & 201597047 & $\mathrm{Cgc} / \mathrm{Tgc}$ & R1223C & 0.00 & D & D & D & $0.004 \|$ \\
\hline IFT46 & 869 & 145438119 & $\mathrm{Cct} / \mathrm{Gct}$ & P152A & 0.03 & $\mathrm{D}$ & $\mathrm{D}$ & $\mathrm{D}$ & $0.007 \|$ \\
\hline IFT52 & 1314 & 148727335 & Gag/Aag & E282K & 0.17 & $P$ & D & D & $0.001 \S$ \\
\hline IFT80 & $588 / 612$ & 375941259 & Cga/Tga & $\mathrm{R} 734^{*}$ & ND & ND & $\mathrm{D}$ & U & $0.0002 \S$ \\
\hline IFT88 & 869 & - & $\mathrm{Gtt} / \mathrm{Ttt}$ & V704F & 0.01 & $\mathrm{P}$ & ND & D & No \\
\hline NEDD9 & $41 / 646$ & 34265420 & $\mathrm{cCa} / \mathrm{cAa}$ & P136Q & 0.00 & D & D & $\mathrm{N}$ & $0.004 \|$ \\
\hline NPHP4 & 841 & 527701970 & $\mathrm{cCg} / \mathrm{cTg}$ & P301L & 0.00 & $\mathrm{P}$ & ND & $D$ & $0.0002 \S$ \\
\hline \multirow{2}{*}{ TMEM67 } & 698 & 202149403 & $\mathrm{aTg} / \mathrm{aCg}$ & M252T & 0.00 & $B$ & $\mathrm{D}$ & $\mathrm{D}$ & $0.0002 \S$ \\
\hline & 612 & 137853108 & Aga/Tga & $\mathrm{R}^{208^{*}}$ & ND & ND & $\mathrm{D}$ & ND & $0.0002 \S$ \\
\hline
\end{tabular}

SIFT, scale-invariant feature transform prediction method; PolyPhen2: LRT, likelihood ratio test; B, benign; P, possibly damaging; D, probably damaging; mutation taster: N, nondisease causing; D, disease causing; LTR: U, unknown; N, neutral; D, deleterious; ND, not determined; no, not present in these databases. For expansions of gene names, see the text or the abbreviations list.

* Stopcodon.

† SIFT: value $<0.05$ is regarded as damaging.

¥ Mutation in the gene associated with obesity in human and/or mouse.

$\S$ ExAc database non-Finish European frequencies.

|| Genome of the Netherlands. 
damaging impact on the proteins related to cilia function in extremely obese subjects. However, the actual involvement of this genetic variation in the risk for (extreme) obesity remains to be shown.

Another case (yet unreported data) concerns a male individual with early-onset severe obesity and anosmia. Exome sequencing revealed compound heterozygosity with two mutations in the ADCY3 gene. One mutation is a frameshift (Gly423fs) retaining only one-third of the correct polypeptide sequence, whereas the other mutation is a deletion of a phenylalanine (Phe1118del). Using Provean prediction software (provean.jcvi.org), this mutation was classified as 'deleterious'. This finding in a male patient confirms the link between obesity and cilia function via the $A D C Y 3$ gene as previously reported for $A d c y 3$-knockout mice ${ }^{(113,114)}$.

Although we did not find marked variation in the gene for RPGRIP1L in the thirty extremely obese subjects, from a genetic point of view this ciliary gene is particularly interesting, because its $5^{\prime}$ end is only $100 \mathrm{bp}$ from that of the gene for FTO, with overlapping promoters. FTO is one of the most studied genes in relation to the genetic risk for obesity. However, it has become clear that the FTO gene is part of a chromosomal segment, in which several genes are located that influence weight regulation $^{(137,138)}$

\section{Mechanistic role of cilia in obesity}

Several mechanisms of how mutations in ciliary genes can contribute to increased body weight have been proposed $^{(139-143)}$. In this study, we focus on three possible mechanisms: adipogenesis, central signalling of food intake and odour perception. Although these mechanisms are separately discussed, it should be kept in mind that mutations in cilia genes are pleiotropic and can increase the risk for obesity via more than one mechanism.

\section{A primary cilium for adipogenesis}

Adipogenesis occurs as a result of two opposing forces based on pro-adipogenic factors such as insulin-like growth factor 1 receptor (IGF1-R), CAATT/enhancer binding protein $\alpha-\beta$ (CEBP/A-B) and PPAR $\gamma$ and on anti-adipogenic signalling pathways such as $\mathrm{SHH}$, wingless-type MMTV integration site regulatory gene/pathway (Wnt) and Notch. Ciliary proteins may influence either one or both of these forces, and have therefore been referred to as gatekeepers of adipocyte differentiation ${ }^{(144)}$. Marion et $a l{ }^{(144)}$ showed that the reduced expression of the BBS12 gene in mesenchymal stem cells down-regulated the anti-adipogenic pathways but promoted the pro-adipogenic factors. On the other hand, a decrease in Alms1, Ift88 or Kif3a expression inhibits cilium formation, as well as also adipocyte differentiation in mouse 3T3-L1 cells ${ }^{(145,146)}$

When human pre-adipocytes in vitro were induced to differentiate to mature white adipocytes, it was observed that a primary cilium appeared on the pre-adipocytes when cell cultures became confluent. Immunostaining showed in the cilium the presence of receptors involved in the SHH and Wnt signalling ${ }^{(147)}$. Similar observations were made in cultures of mouse 3T3-L1 pre-adipocytes, where a primary cilium together with $\alpha$-tubulin acetylation was induced in growth-arrested confluent cells ${ }^{(146)}$. In those cells, a sensitised form of the IGF1-R, an important pro-adipogenic factor, was also detected in the cilium. Cilium formation could be inhibited by the suppression of Ift88 or the kinesin Kif3a ${ }^{(146)}$

Recently, the process of cilium formation was studied in more detail using in vitro differentiation of human mesenchymal stem cells into adipocytes. Within the first $2 \mathrm{~d}$ of differentiation, the primary cilium was observed to elongate together with increased trafficking of IGF1-R $\beta$ into the cilium. This elongation process could be inhibited by insulin or by reduced IFT88 expression $^{(148)}$. Similar information was obtained with in vitro differentiation of human adipose stem cells ${ }^{(149)}$. During the first few days after confluence, the primary cilium appeared and elongated, but thereafter it decreased in size to the stage where cells began to accumulate lipids. At that stage, the cilium completely disappeared. On day 3, approximately at the maximal length of the cilium, SHH signalling was reduced by $50 \%$ as compared with undifferentiated cells. However, there is no definite proof that cilium length and SHH signalling are linked. Final disassembly of the cilium may involve the deacetylation of $\alpha$-tubulin with microtubule destabilisation, by enzymes such as sirtuin 2 (SIRT2) and HDAC6 ${ }^{(150)}$. Recently, the transient occurrence of the primary cilium during differentiation of human adipose stem cells was observed with disappearance of the cilium at the beginning of lipid accumulation ${ }^{(149)}$.

Altogether, a picture emerges in which the primary cilium behaves like a sensory system that initially elongates and extends through the extracellular matrix (ECM) to monitor signals from the cellular environment ${ }^{(151)}$. This allows the cells to make a go/no go decision for differentiation. As the cells mature into lipid-loaded adipocytes, the ECM develops into a strong supportive layer and the cilium disappears.

Genetic variation or mutation in each of the ciliary genes may shift the balance between anti- and pro-adipogenesis differently, which may explain the variation in obesity phenotype between ciliopathy subtypes as mentioned before. In addition, the effect on the level of hyperplasia and hypertrophy may differ per gene. By studying Bbs12-knockout mice ${ }^{(144)}$, it was observed that those mice had a higher number of small-sized to normal-sized adipocytes between hypertrophic cells than the wild-type mice. As small adipocytes are supposed to have a more healthy metabolic activity ${ }^{(152)}$, this was seen as a possible explanation for the low risk of BBS12 patients to develop type 2 diabetes, whereas in Alström syndrome early-onset type 2 diabetes is common ${ }^{(20,153)}$. Knockdown of Alms1 in murine 3T3-L1 pre-adipocytes reduced pre-adipocyte differentiation by 2 -fold ${ }^{(145)}$, suggesting that obesity in Alström patients is accompanied mainly by hypertrophy.

Assuming that cilia monitor signals from the environment, it would be interesting to know how the genes mentioned here respond to changes in energy availability, but not much data have been reported. For eleven patients with obesity and type 2 diabetes, who underwent bariatric surgery, microarray analysis of blood cell RNA was performed before and 6 months after the surgery $^{(154)}$. IFT121/WDR35 was among the seven genes, of 


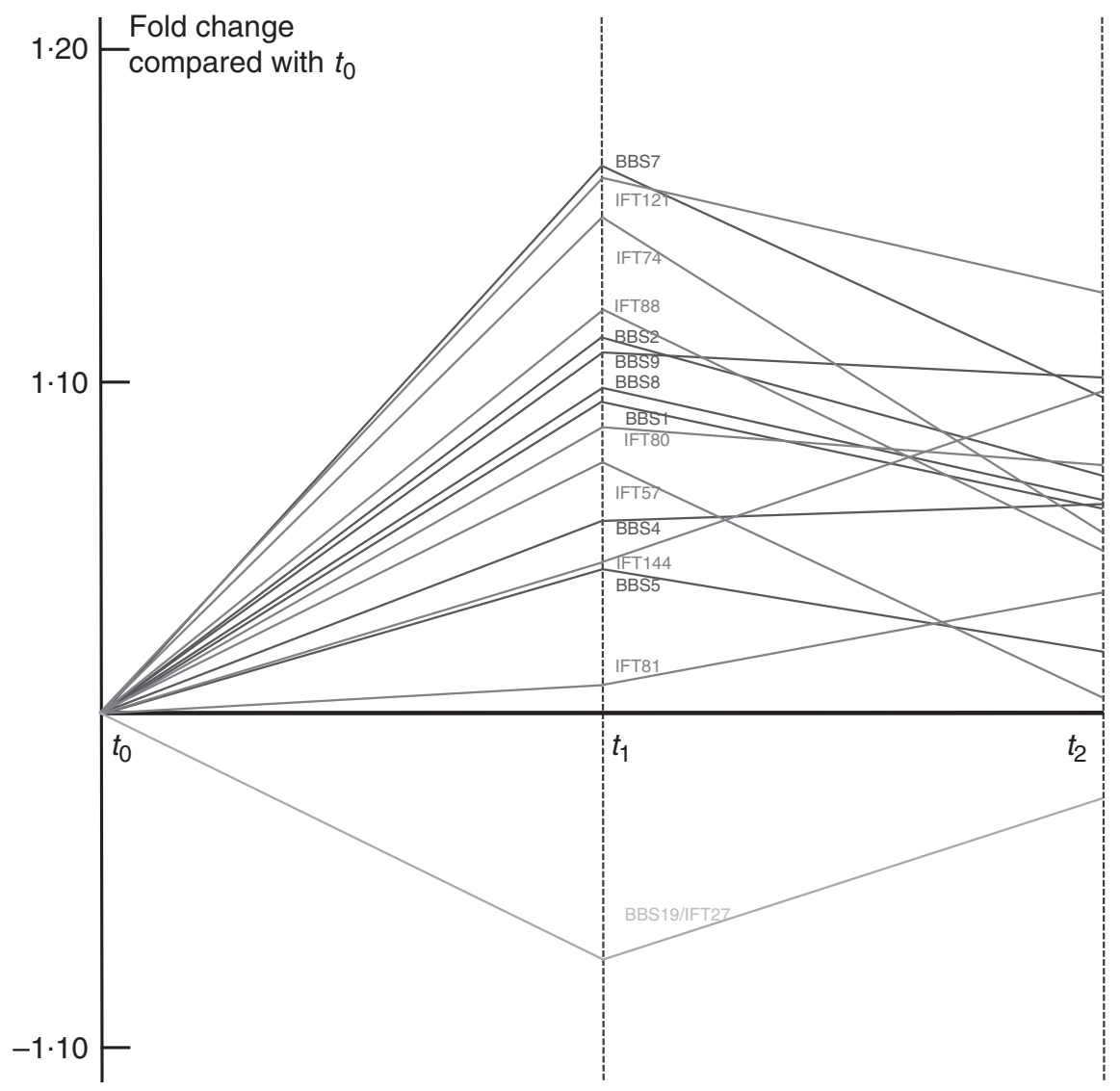

Fig. 2. Changes in expressions of genes coding for proteins of the basal transport complex (BTC) during energy restriction $\left(t_{0}-t_{1}\right)$ and balanced energy intake $\left(t_{1}-t_{2}\right)$. Expression changes are indicated as average $(n 53)$ fold changes at $t_{1}$ and $t_{2}$ compared with $t_{0}$. — , BBSome components; — components of the intraflagellar transport (IFT) particles; —_, changes in gene expression of BBS19/IFT27.

which the change in gene expression was strongly correlated with change in body weight, fasting plasma glucose and glycosylated $\mathrm{Hb}$ content.

To obtain further insight, we analysed gene expression data of fifty-three obese subjects who had lost approximately $10 \%$ of their body weight either rapidly in 5 weeks or more gradually in 12 weeks on an energy-restricted diet, as reported elsewhere ${ }^{(155)}$. Adipose tissue RNA levels were measured by Affimetrix microarrays at the start of energy restriction $\left(t_{0}\right)$, at the end of energy restriction ( $t_{1}, 5$ or 12 weeks) and after subsequently having been on a weight-stable diet for 4 weeks $\left(t_{2}\right)$. Fig. 2 shows the relative expression levels over time of fifteen genes coding for components of the BTC. In all, fourteen of the fifteen BTC genes were up-regulated during energy restriction. For half of the genes, the measured up-regulation was significant $(P \leq 0.01)$. The average up-regulation was $8 \%$, with the genes for BBS2, BBS7 and BBS9, from which the BBSome assembly starts ${ }^{(87)}$, showing the highest up-regulation of $11 \%(P<0.001), 17 \%(P<0.001)$ and $11 \%(P=0.002)$, respectively. This suggests that energy restriction stimulates IFT. Remarkably, the gene for BBS19/IFT27 was down-regulated by $7 \%$. This would leave BBS3/ARL6 more available for binding GTP, which would promote retrograde transport with possible (functional) decline of the cilium ${ }^{(93)}$. Such BTC profile might shift the balance between pro- and anti-adipogenic processes towards adipogenesis. An increased adipogenic capacity of the adipose tissue after energy restriction has been observed ${ }^{(156)}$.

\section{The cilium in neuronal food intake regulation}

The hypothalamic neurons of genetic mouse models for obesity (ob/ob, db/db) have shorter cilia compared with lean mice $(\mathrm{C} 57 \mathrm{BL} / 6)^{(157)}$. The same observation was made for dietinduced obese mice with leptin resistance after a 14-week, high-energy diet. When 36-h fasted C57BL/6 mice were compared with mice that were re-fed afterwards for $6 \mathrm{~h}$, an increased frequency of short cilia was seen after the fast and a higher frequency of longer cilia after the re-feeding ${ }^{(157)}$. Cilia length in these genetic models could be corrected by leptin supplementation, suggesting that the cilium length is increased by leptin. Using N1 hypothalamic neuronal cells in vitro, it was confirmed that leptin does not promote the number of ciliated cells, but increases cilium length ${ }^{(158)}$. This process seemed to depend on destabilisation of F-actin.

Rahmouni et al. ${ }^{(159)}$ developed knockout mice for Bbs2, Bbs4 and Bbs6, which all showed increased food intake, body mass and fat mass. Administration of leptin could not bring down food intake and body weight, showing that these $\mathrm{Bbs}^{-/-}$mice are leptin resistant. Gene expression measurements pointed to 
a defect in the pro-opiomelanocortin (POMC) neurons of the hypothalamus. Indeed, disruption of the cilia on the POMC neurons of the hypothalamus led to the obesity phenotype in mice $^{(160)}$. In an additional study, it was shown that the leptin receptor interacts with BBS1, and that down-regulation of BBS1 or BBS2 in ARPE-12 cells induces mislocalisation of the leptin receptor $^{(161)}$. Altogether, this suggests that the leptin receptor is transported by the BBSome into the cilia of hypothalamic POMC neurons and that a defect in this system results in hyperphagia, obesity and leptin resistance. Studying a conditional Ift88 deletion mutant with absence of cilia in the hypothalamus, Berbari et al. showed that leptin resistance only occurred in adult mice after they had become obese ${ }^{(162)}$. This observation was confirmed in the Bbs4-knockout study. It was concluded that leptin resistance is a secondary effect of obesity and not the cause.

Hypothalamic neurons also function in signalling pathways other than leptin signalling related to energy intake and energy homoeostasis. Probably, the cilia are key players in those processes as well. Loktev and Jackson showed that the cilia of hypothalamic neurons contain receptors for the orexigenic neuropeptide $\mathrm{Y}^{(163)}$. Moreover, the melanin-concentrating hormone receptor 1 (Mchr1), which is involved in food intake regulation, is normally present in the primary cilium. According to Berbari et al. ${ }^{(164)}$, Mchr1 is not properly taken up in the cilia of Bbs2- and Bbs4-knockout mice, causing over-activation of the orexigenic melanin-concentrating hormone (MCH)signalling pathway. In humans, association studies between the MCHR1 gene and parameters of obesity are conflicting, which may be because of epigenetic effects ${ }^{(165)}$.

Studying the obese/hyperphagic Ankrd26-knockout mouse, Acs et al. ${ }^{(78)}$ recently demonstrated absence of Adcy3containing primary cilia in the paraventricular nucleus, a part of the hypothalamus involved in food intake regulation. Similarly, disrupting the function of the Alms 1 gene leads to a large decrease of ciliated neurons in the hypothalamus as determined by the absence of Adcy3, Mchr1 and somatostatin receptor 3 $\left(\right.$ Sstr3) ${ }^{(166)}$.

In summary, the findings indicate that cilia on hypothalamic neurons, particularly on the POMC neurons, contain the receptors for hormones that regulate food intake such as leptin, neuropeptide $\mathrm{Y}$ and $\mathrm{MCH}$. Therefore, those cilia and their proper functioning are important for weight regulation. Either a reduction in the number of cilia or a change in length, which may be influenced by leptin, may induce hyperphagia and obesity.

\section{Sensory cilia for odour perception}

A reduction or ablation of odour perception referred to as hyposmia and anosmia, respectively, is a symptom of various ciliopathies. Hyposmia and anosmia have been shown to be cardinal and constant features in $\mathrm{BBS}^{(167)}$. A disturbance of the olfactory system has been shown in patients with BBS1, BBS3, BBS4, BBS5, BBS9, BBS10, BBS12 and BBS17, syndromes that are all associated with obesity (Table 1$)^{(24,28,37,167)}$.

Additional information on the link between ciliary genes, disturbed olfaction and weight regulation comes from animal studies. For several genes including Bbs1, Bbs2, Bbs4, Bbs6 and $B b s 8^{(24,159,168)}$, genetic manipulation is accompanied by olfactory dysfunction, hyperphagia and/or increased weight. Knockout mice of Bbs1 and Bbs 4 are runts of the litter at birth, but $10 \%$ of them become obese at week $10^{(24)}$. Their odourant signalling is disturbed and the cilia of the olfactory epithelium show structural abnormalities with severe affection of the axoneme. In addition, the microtubular organisation of the dendrites is damaged ${ }^{(24)}$. Bbs2-knockout mice present with a deficit of olfaction and altered social behaviour ${ }^{(169)}$. Olfactory dysfunction presenting as partial or complete anosmia is also observed in the knockout of Bbs6/Mkks (McKusick-Kaufman syndrome $)^{(170)}$. In the $B b s 8$ knockout, a loss of olfactory cilia from the olfactory sensory neurons is observed as well as an altered pattern of axon targets ${ }^{(168)}$. Weight gain is slow at young age but eventually the adult mice develop obesity, which is especially pronounced in the females.

The IFT proteins have been far less studied than the BBS proteins for their possible involvement in olfaction and obesity. Knock-down of Ift46 in the zebrafish led, among others, to disturbed ciliogenesis in the olfactory pits ${ }^{(171)}$. Similar observations have been made by Halbritter et al. ${ }^{(124)}$ concerning a knock-down of Ift172 with defective and shortened cilia in the zebrafish olfactory placode. A nonsense mutation in the gene for CLUAP1, supposed to be a part of the IFT-B particle, leads to absence of cilia from the olfactory pit of the zebrafish ${ }^{(171)}$. However, in none of those studies, a link with weight regulation was made. Mice homozygous for a hypomorphic mutation in the Ift 88 gene display polycystic kidney disease, underweight in litters and olfactory dysfunction, but do not develop obesity. However, this is suggested to be due to early death and health issues from multiple organ malfunction ${ }^{(172)}$. Ciliopathy in animals is not always accompanied by obesity, which is comparable with the situation in man. Moreover, direct evidence between cilia-related olfactory dysfunction and overweight/ obesity is not yet available.

In more general sense, olfactory dysfunction may cause weight change, but does not always lead to overweight/obesity. Acquired hyposmia and anosmia may lead to all possible outcomes: either weight loss, weight gain or no change in weight $^{(173)}$. Aschenbrenner et al. ${ }^{(174)}$ found weight gain in $21 \%$ of patients with acquired reduced sense of smell, whereas $11 \%$ lost weight. Duration and severity of the affection and age may be of influence. Weight gain under olfactory deficiency is explained by a compensatory intake of nutrients, such as a higher amounts of sugar. Acquired reduction of smell in elderly women was observed to be associated with increased fat intake, suggesting risk for obesity ${ }^{(175)}$. In a small sample of persons with congenital anosmia ( $n$ 41), fifteen were overweight, which was significantly less than the expected twenty-six based on the frequency of overweight in the general population $^{(174)}$

Although the relationship between the cilia-mediated olfactory system and overweight/obesity can be complex, a link on the molecular basis can be demonstrated. The olfactory sensory neurons form a dendritic knob from which sensory cilia protrude through the mucus layer of the nasal cavity. Those sensory cilia carry the olfactory receptors (OR), which are 
transported into the cilia by the $\mathrm{BTC}^{(84,176)}$. As such, the cilium forms a link between the environment and the brain. Odourous compounds bind to the receptors, leading to depolarisation of the olfactory sensory cell ${ }^{(177)}$. This signal is transferred to the mitral cells, to which the sensory neuron is attached in the glomerulus of the olfactory bulb. From there, the signal is sent on to the hypothalamus and other regions in the brain. Experiments in the mouse have indicated that fluctuations in the level of secondary messengers, which in part are controlled by cyclases and phosphodiesterases, influence the way in which signals from odour-binding receptors are transferred $^{(178)}$. Cilia-based olfactory defects may also relate to changes in the grey matter of the brain as shown by Braun et $a{ }^{(167)}$.

As the cilium is the intermediate in the signal from the environment to the brain, variation in the functioning of OR can be regarded as a mimetic for variation in the functioning of sensory cilia. In this regard, it is interesting to notice that genetic studies have shown a link between OR and food intake/obesity. Genetic association was demonstrated between OR7 genes and eating behaviour and adiposity ${ }^{(179)}$. Further, a copy number variant at chromosome 11q11 covering three OR genes, OR4P4, OR4S2 and OR4C6, was found to be associated with obesity $^{(180)}$. In addition, we have reported associations between genetic variation in the OR14C36 gene and extreme obesity $^{(135)}$

Besides the OR, the neuronal connections between olfactory sensory neurons and the mitral cells in the glomerulus are important for food intake regulation. Removing the olfactory bulb from $\mathrm{Kv} 1 \cdot 3^{-/-}$mice abolishes their resistance to dietinduced obesity ${ }^{(181)}$. It has been proposed that the development of the neuronal connections in the glomerulus depends on two opposing processes, axon guidance and repulsion, and involves both OR and clustered protocadherin genes ${ }^{(182)}$. We recently reported a relationship between genetic variation in the clustered protocadherin genes on chromosome $5 q$ and extreme obesity ${ }^{(134)}$. Moreover, a genetic interaction between OR genes on chromosome $1 \mathrm{q}$ and the protocadherin- $\beta$ genes has been observed in this extreme obesity cohort ${ }^{(135)}$.

Notably, food odour can stimulate appetite, food-seeking behaviour and food ingestion, but strong or prolonged exposure to a food odour can have a satiating effect ${ }^{(183)}$. In this regard, stimulation of sensory cilia may induce increased appetite and food intake. On the other hand, diminished ciliary signalling of the OR neurons in ciliopathy syndromes might reduce satiating cues by food odours and promote food intake and obesity as well. This duality in the response to food odours complicates studies on the relationship between olfaction and obesity risk. Moreover, food perception and response is subject to the metabolic status ${ }^{(184)}$. Stafford \& Whittle ${ }^{(185)}$ showed that the preference and sensitivity to the odour of chocolate were different between obese and non-obese subjects. The property to vividly image flavours and aromas was found to be associated with $\mathrm{BMI}^{(186)}$. Despite this complex interaction between food odour and food intake, it is clear that cilia, particularly the sensory cilia, are essential for this process, and in this respect olfactory sensory cilia function may influence the risk for obesity.

\section{Perspective on general obesity}

As cilia are relevant for the proper development and performance of many cell types, organs and tissues, a mutation or, more in general, variation in a ciliary gene usually gives rise to pleiotropic effects. As a consequence, variation of a ciliary gene may contribute to the obesity risk from a broad spectrum of processes, including pre-adipocyte differentiation, hypothalamic regulation of food intake and olfactory perception and response. Despite the limited impact of variation in ciliary genes on obesity in general, the fact that those genes are players in various aetiological processes makes them an interesting target for intervention. The obesity phenotype in ciliopathies is a consequence of mutations that impair protein function. Therefore, overexpression of ciliary genes may provide a genetherapeutic way to prevent obesity. Experiments with overexpression have been carried out to rescue the retinal phenotype of the Bbs1 knock-in mouse ${ }^{(128)}$. Overexpression of Bbs1 by AAV-Bbs1 injection into the retina improved symptoms of retinal degeneration. However, injection into the retina of WT mice led to outer retinal degeneration, demonstrating the potential risk of overexpression toxicity ${ }^{(187)}$. Perhaps a safer approach to explore the possibility of overexpression would be to aim for odour perception as part of the obesity risk via the olfactory sensory cells. The epithelium of the nose can be readily treated by gene therapy using non-invasive intranasal gene delivery ${ }^{(140)}$. As a demonstration of this application, adenovirus-mediated delivery of Ift88 to olfactory sensory nerves has led to restoration of the olfactory function in the Oak Ridge polycystic kidney disease (ORPK) mouse ${ }^{(51)}$.

In a more optimal approach for obesity treatment, manipulation of ciliary gene expression should be performed by addressing various tissues to reduce simultaneously food craving, energy intake and fat storage in the adipose tissue. For this, drug therapy would be an attractive method. An example of potential drugs in this respect, although perhaps not very specific for mutations in ciliary genes, is the group of phosphodiesterase inhibitors, which can influence the level of second messengers. Not only can they have an effect on olfaction $^{(178)}$ but also on pre-adipocyte differentiation ${ }^{(188)}$ and on leptin signalling in the hypothalamus ${ }^{(189)}$. Moreover, phosphodiesterase inhibitors exist as natural food components ${ }^{(190)}$, although they have to be used with caution ${ }^{(191)}$. More knowledge on cilia and ciliary genes in relation to the risk of obesity should provide more specific ways for prevention and treatment in the future.

\section{Acknowledgements}

The authors thank the Department of Human Genetics, Maastricht University Medical Centre (MUMC+), for providing the necessary infrastructure.

This study was funded by Netherlands Organisation for Scientific Research (NWO, TOP grant no. 200500001). NWO had no role in the design, analysis or writing of this article.

E. C. M. M. contributed to the design, contents and writing of the review, by analysing genetic data and by drawing the figures; R. G. V., N. J. T. R. and M. A. v. B. contributed by providing and 
analysing gene expression data; F. B., E. E. J. G. A., M. A. v. B. and C. T. R. M. S. contributed by providing genetic data; P. W. contributed to the design, to the scientific contents and writing. All the authors helped to improve the manuscript by critical evaluation.

There are no conflicts of interest.

\section{Supplementary material}

To view supplementary material for this article, please visit http://dx.doi.org/10.1017/S0007114516002282

\section{References}

1. Benzing T \& Schermer B (2011) Transition zone proteins and cilia dynamics. Nat Genet 43, 723-724.

2. Garcia-Gonzalo FR, Corbit KC, Sirerol-Piquer MS, et al. (2011) A transition zone complex regulates mammalian ciliogenesis and ciliary membrane composition. Nat Genet 43, 776-784.

3. Reiter JF, Blacque OE \& Leroux MR (2012) The base of the cilium: roles for transition fibres and the transition zone in ciliary formation, maintenance and compartmentalization. EMBO Rep 13, 608-618.

4. Sang L, Miller JJ, Corbit KC, et al. (2011) Mapping the NPHPJBTS-MKS protein network reveals ciliopathy disease genes and pathways. Cell 145, 513-528.

5. Satir P, Pedersen LB \& Christensen ST (2010) The primary cilium at a glance. I Cell Sci 123, 499-503.

6. Szymanska K \& Johnson CA (2012) The transition zone: an essential functional compartment of cilia. Cilia 1, 10.

7. Valente EM, Rosti RO, Gibbs E, et al. (2014) Primary cilia in neurodevelopmental disorders. Nat Rev Neurol $\mathbf{1 0}$, $27-36$.

8. Garcia-Gonzalo FR \& Reiter JF (2012) Scoring a backstage pass: mechanisms of ciliogenesis and ciliary access. $J$ Cell Biol 197, 697-709.

9. Boekhoff I, Tareilus E, Strotmann J, et al. (1990) Rapid activation of alternative second messenger pathways in olfactory cilia from rats by different odorants. EMBO $J \mathbf{9}$, 2453-2458.

10. Corbit KC, Shyer AE, Dowdle WE, et al. (2008) Kif3a constrains beta-catenin-dependent Wnt signalling through dual ciliary and non-ciliary mechanisms. Nat Cell Biol 10 $70-76$.

11. Goetz SC \& Anderson KV (2010) The primary cilium: a signalling centre during vertebrate development. Nat Rev Genet 11, 331-344.

12. Rohatgi R, Milenkovic L \& Scott MP (2007) Patched1 regulates hedgehog signaling at the primary cilium. Science 317, 372-376.

13. Schneider L, Clement CA, Teilmann SC, et al. (2005) PDGFRalphaalpha signaling is regulated through the primary cilium in fibroblasts. Curr Biol 15, 1861-1866.

14. Baker K \& Beales PL (2009) Making sense of cilia in disease: the human ciliopathies. Am J Med Genet C Semin Med Genet 151C, 281-295.

15. Leitch CC, Zaghloul NA, Davis EE, et al. (2008) Hypomorphic mutations in syndromic encephalocele genes are associated with Bardet-Biedl syndrome. Nat Genet $\mathbf{4 0}$ $443-448$

16. Forsythe E \& Beales PL (2003) Bardet-Biedl Syndrome In GeneReviews(R), pp. 1993-2016 [RA Pagon, MP Adam, HH Ardinger, SE Wallace, A Amemiya, LJH Bean, TD Bird,
CR Dolan, CT Fong, RJH Smith and K Stephens, editors]. Seattle, WA: University of Washington.

17. Hampshire DJ, Ayub M, Springell K, et al. (2006) MORM syndrome (mental retardation, truncal obesity, retinal dystrophy and micropenis), a new autosomal recessive disorder, links to 9q34. Eur J Hum Genet 14, 543-548.

18. Jacoby M, Cox JJ, Gayral S, et al. (2009) INPP5E mutations cause primary cilium signaling defects, ciliary instability and ciliopathies in human and mouse. Nat Genet 41, 1027-1031.

19. Shalata A, Ramirez MC, Desnick RJ, et al. (2013) Morbid obesity resulting from inactivation of the ciliary protein CEP19 in humans and mice. Am I Hum Genet 93 , 1061-1071.

20. Marshall JD, Maffei P, Collin GB, et al. (2011) Alstrom syndrome: genetics and clinical overview. Curr Genomics 12, 225-235.

21. Thomas S, Cantagrel V, Mariani L, et al. (2015) Identification of a novel ARL13B variant in a Joubert syndrome-affected patient with retinal impairment and obesity. Eur J Hum Genet 23, 621-627.

22. Hopp K, Heyer CM, Hommerding CJ, et al. (2011) B9D1 is revealed as a novel Meckel syndrome (MKS) gene by targeted exon-enriched next-generation sequencing and deletion analysis. Hum Mol Genet 20, 2524-2534.

23. Harville HM, Held S, Diaz-Font A, et al. (2010) Identification of 11 novel mutations in eight BBS genes by high-resolution homozygosity mapping. J Med Genet 47, 262-267.

24. Kulaga HM, Leitch CC, Eichers ER, et al. (2004) Loss of BBS proteins causes anosmia in humans and defects in olfactory cilia structure and function in the mouse. Nat Genet 36, 994-998.

25. M'Hamdi O, Redin C, Stoetzel C, et al. (2014) Clinical and genetic characterization of Bardet-Biedl syndrome in Tunisia: defining a strategy for molecular diagnosis. Clin Genet 85, 172-177.

26. Bee YM, Chawla M \& Zhao Y (2015) Whole exome sequencing identifies a novel and a recurrent mutation in Bbs2 gene in a family with Bardet-Biedl syndrome. Biomed Res Int 2015, 524754.

27. Sheffield VC, Carmi R, Kwitek-Black A, et al. (1994) Identification of a Bardet-Biedl syndrome locus on chromosome 3 and evaluation of an efficient approach to homozygosity mapping. Hum Mol Genet 3, 1331-1335.

28. Iannaccone A, Mykytyn K, Persico AM, et al. (2005) Clinical evidence of decreased olfaction in Bardet-Biedl syndrome caused by a deletion in the BBS4 gene. Am J Med Genet A 132A, 343-346.

29. Hjortshoj TD, Gronskov K, Philp AR, et al. (2008) Novel mutations in BBS5 highlight the importance of this gene in non-Caucasian Bardet-Biedl syndrome patients. Am J Med Genet $A$ 146A, 517-520.

30. Slavotinek AM, Stone EM, Mykytyn K, et al. (2000) Mutations in MKKS cause Bardet-Biedl syndrome. Nat Genet 26, $15-16$.

31. Nishimura DY, Swiderski RE, Searby CC, et al. (2005) Comparative genomics and gene expression analysis identifies BBS9, a new Bardet-Biedl syndrome gene. Am J Hum Genet 77, 1021-1033.

32. Lim ET, Liu YP, Chan Y, et al. (2014) A novel test for recessive contributions to complex diseases implicates Bardet-Biedl syndrome gene BBS10 in idiopathic type 2 diabetes and obesity. Am J Hum Genet 95, 509-520.

33. Chiang AP, Beck JS, Yen HJ, et al. (2006) Homozygosity mapping with SNP arrays identifies TRIM32, an E3 ubiquitin ligase, as a Bardet-Biedl syndrome gene (BBS11). Proc Natl Acad Sci U S A 103, 6287-6292. 
34. Saccone V, Palmieri M, Passamano L, et al. (2008) Mutations that impair interaction properties of TRIM32 associated with limb-girdle muscular dystrophy 2H. Hum Mutat 29, 240-247.

35. Xing DJ, Zhang HX, Huang N, et al. (2014) Comprehensive molecular diagnosis of Bardet-Biedl syndrome by highthroughput targeted exome sequencing. PLOS ONE 9, e90599.

36. Logan CV, Abdel-Hamed Z \& Johnson CA (2011) Molecular genetics and pathogenic mechanisms for the severe ciliopathies: insights into neurodevelopment and pathogenesis of neural tube defects. Mol Neurobiol 43, 12-26.

37. McEwen DP, Koenekoop RK, Khanna H, et al. (2007) Hypomorphic CEP290/NPHP6 mutations result in anosmia caused by the selective loss of $G$ proteins in cilia of olfactory sensory neurons. Proc Natl Acad Sci USA 104, 15917-15922.

38. Sayer JA, Otto EA, O’Toole JF, et al. (2006) The centrosomal protein nephrocystin-6 is mutated in Joubert syndrome and activates transcription factor ATF4. Nat Genet 38, 674-681.

39. Baala L, Audollent S, Martinovic J, et al. (2007) Pleiotropic effects of CEP290 (NPHP6) mutations extend to Meckel syndrome. Am J Hum Genet 81, 170-179.

40. Kim SK, Shindo A, Park TJ, et al. (2010) Planar cell polarity acts through septins to control collective cell movement and ciliogenesis. Science 329, 1337-1340.

41. Billingsley G, Vincent A, Deveault C, et al. (2012) Mutational analysis of SDCCAG8 in Bardet-Biedl syndrome patients with renal involvement and absent polydactyly. Ophthalmic Genet 33, 150-154.

42. Otto EA, Hurd TW, Airik R, et al. (2010) Candidate exome capture identifies mutation of SDCCAG8 as the cause of a retinal-renal ciliopathy. Nat Genet 42, 840-850.

43. Marion V, Stutzmann F, Gerard M, et al. (2012) Exome sequencing identifies mutations in LZTFL1, a BBSome and smoothened trafficking regulator, in a family with Bardet-Biedl syndrome with situs inversus and insertional polydactyly. J Med Genet 49, 317-321.

44. Scheidecker S, Etard C, Pierce NW, et al. (2014) Exome sequencing of Bardet-Biedl syndrome patient identifies a null mutation in the BBSome subunit BBIP1 (BBS18). J Med Genet 51, 132-136.

45. Aldahmesh MA, Li Y, Alhashem A, et al. (2014) IFT27, encoding a small GTPase component of IFT particles, is mutated in a consanguineous family with Bardet-Biedl syndrome. Hum Mol Genet 23, 3307-3315.

46. Tallila J, Jakkula E, Peltonen L, et al. (2008) Identification of CC2D2A as a Meckel syndrome gene adds an important piece to the ciliopathy puzzle. Am J Hum Genet 82, $1361-1367$.

47. Gorden NT, Arts HH, Parisi MA, et al. (2008) CC2D2A is mutated in Joubert syndrome and interacts with the ciliopathy-associated basal body protein CEP290. Am J Hum Genet 83, 559-571.

48. Bouhouche A, Benomar A, Bouslam N, et al. (2006) Mutation in the epsilon subunit of the cytosolic chaperonincontaining t-complex peptide-1 (Cct5) gene causes autosomal recessive mutilating sensory neuropathy with spastic paraplegia. J Med Genet 43, 441-443.

49. Arts HH, Bongers EM, Mans DA, et al. (2011) C14ORF179 encoding IFT43 is mutated in Sensenbrenner syndrome. J Med Genet 48, 390-395.

50. Tuysuz B, Baris S, Aksoy F, et al. (2009) Clinical variability of asphyxiating thoracic dystrophy (Jeune) syndrome: evaluation and classification of 13 patients. Am J Med Genet A 149A, 1727-1733.
51. McIntyre JC, Davis EE, Joiner A, et al. (2012) Gene therapy rescues cilia defects and restores olfactory function in a mammalian ciliopathy model. Nat Med 18, 1423-1428.

52. Walczak-Sztulpa J, Eggenschwiler J, Osborn D, et al. (2010) Cranioectodermal dysplasia, Sensenbrenner syndrome, is a ciliopathy caused by mutations in the IFT122 gene. Am J Hum Genet 86, 949-956.

53. Davis EE, Zhang Q, Liu Q, et al. (2011) TTC21B contributes both causal and modifying alleles across the ciliopathy spectrum. Nat Genet 43, 189-196.

54. Huynh Cong E, Bizet AA, Boyer O, et al. (2014) A homozygous missense mutation in the ciliary gene TTC21B causes familial FSGS. J Am Soc Nephrol 25, 2435-2443.

55. Schmidts M, Frank V, Eisenberger T, et al. (2013) Combined NGS approaches identify mutations in the intraflagellar transport gene IFT140 in skeletal ciliopathies with early progressive kidney disease. Hum Mutat $\mathbf{3 4}$, 714-724.

56. Perrault I, Saunier S, Hanein S, et al. (2012) Mainzer-Saldino syndrome is a ciliopathy caused by IFT140 mutations. Am J Hum Genet 90, 864-870.

57. Bredrup C, Saunier S, Oud MM, et al. (2011) Ciliopathies with skeletal anomalies and renal insufficiency due to mutations in the IFT-A gene WDR19. Am J Hum Genet 89, 634-643.

58. Bujakowska KM, Zhang Q, Siemiatkowska AM, et al. (2015) Mutations in IFT172 cause isolated retinal degeneration and Bardet-Biedl syndrome. Hum Mol Genet 24, 230-242.

59. Lucas-Herald AK, Kinning E, Iida A, et al. (2015) A case of functional growth hormone deficiency and early growth retardation in a child with IFT172 mutations. J Clin Endocrinol Metab 100, 1221-1224.

60. Cole DG, Diener DR, Himelblau AL, et al. (1998) Chlamydomonas kinesin-II-dependent intraflagellar transport (IFT): IFT particles contain proteins required for ciliary assembly in Caenorhabditis elegans sensory neurons. J Cell Biol 141, 993-1008.

61. Travaglini L, Brancati F, Silhavy J, et al. (2013) Phenotypic spectrum and prevalence of INPP5E mutations in Joubert syndrome and related disorders. Eur J Hum Genet 21, 1074-1078.

62. Ala-Mello S, Koskimies O, Rapola J, et al. (1999) Nephronophthisis in Finland: epidemiology and comparison of genetically classified subgroups. Eur J Hum Genet 7, 205-211.

63. Parisi MA, Bennett CL, Eckert ML, et al. (2004) The NPHP1 gene deletion associated with juvenile nephronophthisis is present in a subset of individuals with Joubert syndrome. Am J Hum Genet 75, 82-91.

64. Caridi G, Murer L, Bellantuono R, et al. (1998) Renal-retinal syndromes: association of retinal anomalies and recessive nephronophthisis in patients with homozygous deletion of the NPH1 locus. Am J Kidney Dis 32, 1059-1062.

65. Schuermann MJ, Otto E, Becker A, et al. (2002) Mapping of gene loci for nephronophthisis type 4 and Senior-Loken syndrome, to chromosome 1p36. Am J Hum Genet $\mathbf{7 0}$, 1240-1246.

66. Thomas S, Wright KJ, Le Corre S, et al. (2014) A homozygous PDE6D mutation in Joubert syndrome impairs targeting of farnesylated INPP5E protein to the primary cilium. Hum Mutat 35, 137-146.

67. Delous M, Baala L, Salomon R, et al. (2007) The ciliary gene RPGRIP1L is mutated in cerebello-oculo-renal syndrome (Joubert syndrome type B) and Meckel syndrome. Nat Genet 39, 875-881. 
68. Doherty D, Parisi MA, Finn LS, et al. (2010) Mutations in 3 genes (MKS3, CC2D2A and RPGRIP1L) cause COACH syndrome (Joubert syndrome with congenital hepatic fibrosis). J Med Genet 47, 8-21.

69. Arts HH, Doherty D, van Beersum SE, et al. (2007) Mutations in the gene encoding the basal body protein RPGRIP1L, a nephrocystin-4 interactor, cause Joubert syndrome. Nat Genet 39, 882-888.

70. Shaheen R, Faqeih E, Seidahmed MZ, et al. (2011) A TCTN2 mutation defines a novel Meckel Gruber syndrome locus. Hum Mutat 32, 573-578.

71. Smith UM, Consugar M, Tee LJ, et al. (2006) The transmembrane protein meckelin (MKS3) is mutated in MeckelGruber syndrome and the wpk rat. Nat Genet 38, 191-196.

72. Romano S, Boddaert N, Desguerre I, et al. (2006) Molar tooth sign and superior vermian dysplasia: a radiological, clinical, and genetic study. Neuropediatrics 37, 42-45.

73. Otto EA, Tory K, Attanasio M, et al. (2009) Hypomorphic mutations in meckelin (MKS3/TMEM67) cause nephronophthisis with liver fibrosis (NPHP11). J Med Genet 46, 663-670.

74. Valente EM, Logan CV, Mougou-Zerelli S, et al. (2010) Mutations in TMEM216 perturb ciliogenesis and cause Joubert, Meckel and related syndromes. Nat Genet 42, 619-625.

75. Edvardson S, Shaag A, Zenvirt S, et al. (2010) Joubert syndrome 2 (JBTS2) in Ashkenazi Jews is associated with a TMEM216 mutation. Am J Hum Genet 86, 93-97.

76. Huang L, Szymanska K, Jensen VL, et al. (2011) TMEM237 is mutated in individuals with a Joubert syndrome related disorder and expands the role of the TMEM family at the ciliary transition zone. Am J Hum Genet 89, 713-730.

77. Kudryashova E, Wu J, Havton LA, et al. (2009) Deficiency of the E3 ubiquitin ligase TRIM32 in mice leads to a myopathy with a neurogenic component. Hum Mol Genet 18, 1353-1367.

78. Acs P, Bauer PO, Mayer B, et al. (2015) A novel form of ciliopathy underlies hyperphagia and obesity in Ankrd26 knockout mice. Brain Struct Funct 220, 1511-1528.

79. Dong C, Li WD, Geller F, et al. (2005) Possible genomic imprinting of three human obesity-related genetic loci. $A m$ J Hum Genet 76, 427-437.

80. Noben-Trauth K, Naggert JK, North MA, et al. (1996) A candidate gene for the mouse mutation tubby. Nature $\mathbf{3 8 0}$, 534-538.

81. Sun X, Haley J, Bulgakov OV, et al. (2012) Tubby is required for trafficking $G$ protein-coupled receptors to neuronal cilia. Cilia 1, 21.

82. Nachury MV, Loktev AV, Zhang Q, et al. (2007) A core complex of BBS proteins cooperates with the GTPase Rab8 to promote ciliary membrane biogenesis. Cell 129, 1201-1213.

83. Jenkins PM, McEwen DP \& Martens JR (2009) Olfactory cilia: linking sensory cilia function and human disease. Chem Senses 34, 451-464.

84. Williams CL, McIntyre JC, Norris SR, et al. (2014) Direct evidence for BBSome-associated intraflagellar transport reveals distinct properties of native mammalian cilia. Nat Commun 5, 5813.

85. Jin H \& Nachury MV (2009) The BBSome. Curr Biol 19, R472-R473.

86. Seo S, Baye LM, Schulz NP, et al. (2010) BBS6, BBS10, and BBS12 form a complex with CCT/TRiC family chaperonins and mediate BBSome assembly. Proc Natl Acad Sci US A 107, 1488-1493.

87. Zhang Q, Yu D, Seo S, et al. (2012) Intrinsic protein-protein interaction-mediated and chaperonin-assisted sequential assembly of stable bardet-biedl syndrome protein complex, the BBSome. J Biol Chem 287, 20625-20635.
88. Loktev AV, Zhang Q, Beck JS, et al. (2008) A BBSome subunit links ciliogenesis, microtubule stability, and acetylation. Dev Cell 15, 854-865.

89. Behal RH, Miller MS, Qin H, et al. (2012) Subunit interactions and organization of the Chlamydomonas reinhardtii intraflagellar transport complex A proteins. J Biol Chem 287, 11689-11703.

90. Rosenbaum JL \& Witman GB (2002) Intraflagellar transport. Nat Rev Mol Cell Biol 3, 813-825.

91. Davis EE \& Katsanis N (2014) Dissecting intraflagellar transport, one molecule at a time. Dev Cell 31, 263-264.

92. Eguether T, San Agustin JT, Keady BT, et al. (2014) IFT27 links the BBSome to IFT for maintenance of the ciliary signaling compartment. Dev Cell 31, 279-290.

93. Liew GM, Ye F, Nager AR, et al. (2014) The intraflagellar transport protein IFT27 promotes BBSome exit from cilia through the GTPase ARL6/BBS3. Dev Cell 31, 265-278.

94. Nachury MV, Seeley ES \& Jin H (2010) Trafficking to the ciliary membrane: how to get across the periciliary diffusion barrier? Annu Rev Cell Dev Biol 26, 59-87.

95. Wiens CJ, Tong Y, Esmail MA, et al. (2010) Bardet-Biedl syndrome-associated small GTPase ARL6 (BBS3) functions at or near the ciliary gate and modulates Wnt signaling. J Biol Chem 285, 16218-16230.

96. Botilde Y, Yoshiba S, Shinohara K, et al. (2013) Cluap1 localizes preferentially to the base and tip of cilia and is required for ciliogenesis in the mouse embryo. Dev Biol 381, 203-212.

97. Lee C, Wallingford JB \& Gross JM (2014) Cluap1 is essential for ciliogenesis and photoreceptor maintenance in the vertebrate eye. Invest Ophthalmol Vis Sci $\mathbf{5 5}$, 4585-4592.

98. Gupta GD, Coyaud E, Goncalves J, et al. (2015) A dynamic protein interaction landscape of the human centrosomecilium interface. Cell 163, 1484-1499.

99. Hearn T, Spalluto C, Phillips VJ, et al. (2005) Subcellular localization of ALMS1 supports involvement of centrosome and basal body dysfunction in the pathogenesis of obesity, insulin resistance, and type 2 diabetes. Diabetes $\mathbf{5 4}$, 1581-1587.

100. Jagger D, Collin G, Kelly J, et al. (2011) Alstrom syndrome protein ALMS1 localizes to basal bodies of cochlear hair cells and regulates cilium-dependent planar cell polarity. Hum Mol Genet 20, 466-481.

101. Leitch CC, Lodh S, Prieto-Echague V, et al. (2014) Basal body proteins regulate Notch signaling through endosomal trafficking. J Cell Sci 127, 2407-2419.

102. Williams CL, Li C, Kida K, et al. (2011) MKS and NPHP modules cooperate to establish basal body/transition zone membrane associations and ciliary gate function during ciliogenesis. J Cell Biol 192, 1023-1041.

103. Gerhardt C, Lier JM, Burmuhl S, et al. (2015) The transition zone protein Rpgrip1l regulates proteasomal activity at the primary cilium. J Cell Biol 210, 115-133.

104. Stratigopoulos G, Martin Carli JF, O'Day DR, et al. (2014) Hypomorphism for RPGRIP1L, a ciliary gene vicinal to the FTO locus, causes increased adiposity in mice. Cell Metab 19, 767-779.

105. Heymsfield SB, Avena NM, Baier L, et al. (2014) Hyperphagia: current concepts and future directions proceedings of the 2nd international conference on hyperphagia. Obesity (Silver Spring) 22, Suppl. 1, S1-S17.

106. Bielas SL, Silhavy JL, Brancati F, et al. (2009) Mutations in INPP5E, encoding inositol polyphosphate-5-phosphatase E, link phosphatidyl inositol signaling to the ciliopathies. Nat Genet 41, 1032-1036. 
107. Chavez M, Ena S, Van Sande J, et al. (2015) Modulation of ciliary phosphoinositide content regulates trafficking and sonic hedgehog signaling output. Dev Cell 34, 338-350.

108. Garcia-Gonzalo FR, Phua SC, Roberson EC, et al. (2015) Phosphoinositides regulate ciliary protein trafficking to modulate hedgehog signaling. Dev Cell 34, 400-409.

109. Park J, Lee N, Kavoussi A, et al. (2015) Ciliary phosphoinositide regulates ciliary protein trafficking in drosophila. Cell Rep 13, 2808-2816.

110. Humbert MC, Weihbrecht K, Searby CC, et al. (2012) ARL13B, PDE6D, and CEP164 form a functional network for INPP5E ciliary targeting. Proc Natl Acad Sci U S A 109, 19691-19696.

111. Nordman S, Abulaiti A, Hilding A, et al. (2008) Genetic variation of the adenylyl cyclase 3 (AC3) locus and its influence on type 2 diabetes and obesity susceptibility in Swedish men. Int J Obes (Lond) 32, 407-412.

112. Wang $\mathrm{H}$, Wu M, Zhu W, et al. (2010) Evaluation of the association between the AC3 genetic polymorphisms and obesity in a Chinese Han population. PLOS ONE 5, e13851.

113. Wang Z, Li V, Chan GC, et al. (2009) Adult type 3 adenylyl cyclase-deficient mice are obese. PLOS ONE 4, e6979.

114. Wong ST, Trinh K, Hacker B, et al. (2000) Disruption of the type III adenylyl cyclase gene leads to peripheral and behavioral anosmia in transgenic mice. Neuron 27, 487-497.

115. Diaz-Font A \& Beales PL (2008) How to shape cells and influence polarized protein trafficking. Dev Cell 15, 799-800.

116. Xu J, Li H, Wang B, et al. (2010) VHL inactivation induces HEF1 and aurora kinase A. J Am Soc Nephrol 21, 2041-2046.

117. Pugacheva EN, Jablonski SA, Hartman TR, et al. (2007) HEF1dependent aurora A activation induces disassembly of the primary cilium. Cell 129, 1351-1363.

118. Plotnikova OV, Seo S, Cottle DL, et al. (2015) INPP5E interacts with AURKA, linking phosphoinositide signaling to primary cilium stability. J Cell Sci 128, 364-372.

119. Yuan X, Serra RA \& Yang S (2015) Function and regulation of primary cilia and intraflagellar transport proteins in the skeleton. Ann N Y Acad Sci 1335, 78-99.

120. Knorz VJ, Spalluto C, Lessard M, et al. (2010) Centriolar association of ALMS1 and likely centrosomal functions of the ALMS motif-containing proteins C10orf90 and KIAA1731. Mol Biol Cell 21, 3617-3629.

121. Seixas C, Choi SY, Polgar N, et al. (2016) Arl13b and the exocyst interact synergistically in ciliogenesis. Mol Biol Cell 27, 308-320.

122. Cui C, Chatterjee B, Lozito TP, et al. (2013) Wdpcp, a PCP protein required for ciliogenesis, regulates directional cell migration and cell polarity by direct modulation of the actin cytoskeleton. PLOS Biol 11, e1001720.

123. Seo S, Zhang Q, Bugge K, et al. (2011) A novel protein LZTFL1 regulates ciliary trafficking of the BBSome and Smoothened. PLoS Genet 7, e1002358.

124. Halbritter J, Bizet AA, Schmidts M, et al. (2013) Defects in the IFT-B component IFT172 cause Jeune and Mainzer-Saldino syndromes in humans. Am J Hum Genet $\mathbf{9 3}$, 915-925.

125. Feuillan PP, Ng D, Han JC, et al. (2011) Patients with BardetBiedl syndrome have hyperleptinemia suggestive of leptin resistance. J Clin Endocrinol Metab 96, E528-E535.

126. Grace C, Beales P, Summerbell C, et al. (2003) Energy metabolism in Bardet-Biedl syndrome. Int J Obes Relat Metab Disord 27, 1319-1324.

127. Cox KF, Kerr NC, Kedrov M, et al. (2012) Phenotypic expression of Bardet-Biedl syndrome in patients homozygous for the common M390R mutation in the BBS1 gene. Vision Res 75, 77-87.
128. Davis RE, Swiderski RE, Rahmouni K, et al. (2007) A knockin mouse model of the Bardet-Biedl syndrome 1 M390R mutation has cilia defects, ventriculomegaly, retinopathy, and obesity. Proc Natl Acad Sci U S A 104, 19422-19427.

129. Carmi R, Elbedour K, Stone EM, et al. (1995) Phenotypic differences among patients with Bardet-Biedl syndrome linked to three different chromosome loci. Am J Med Genet 59, 199-203.

130. Benzinou M, Walley A, Lobbens S, et al. (2006) Bardet-Biedl syndrome gene variants are associated with both childhood and adult common obesity in French Caucasians. Diabetes 55, 2876-2882.

131. Andersen KL, Echwald SM, Larsen LH, et al. (2005) Variation of the McKusick-Kaufman gene and studies of relationships with common forms of obesity. J Clin Endocrinol Metab 90 , 225-230.

132. Birk RZ, Ermakov S \& Livshits G (2013) Common FSNP variants of fourteen Bardet-Biedl syndrome genes and adult body mass. Obesity (Silver Spring) 21, 1684-1689.

133. Reed DR, Ding Y, Xu W, et al. (1995) Human obesity does not segregate with the chromosomal regions of Prader-Willi, Bardet-Biedl, Cohen, Borjeson or Wilson-Turner syndromes. Int J Obes Relat Metab Disord 19, 599-603.

134. Mariman EC, Bouwman FG, Aller EE, et al. (2014) High frequency of rare variants with a moderate-to-high predicted biological effect in protocadherin genes of extremely obese. Genes Nutr 9, 399.

135. Mariman EC, Szklarczyk R, Bouwman FG, et al. (2015) Olfactory receptor genes cooperate with protocadherin genes in human extreme obesity. Genes Nutr 10, 465

136. Li JB, Gerdes JM, Haycraft CJ, et al. (2004) Comparative genomics identifies a flagellar and basal body proteome that includes the BBS5 human disease gene. Cell 117, 541-552.

137. Rask-Andersen M, Almen MS \& Schioth HB (2015) Scrutinizing the FTO locus: compelling evidence for a complex, long-range regulatory context. Hum Genet 134, 1183-1193.

138. Tung YC, Yeo GS, O'Rahilly S, et al. (2014) Obesity and FTO: changing focus at a complex locus. Cell Metab 20, 710-718.

139. Chennen K, Scerbo MJ, Dollfus H, et al. (2014) [Bardet-Biedl syndrome: cilia and obesity - from genes to integrative approaches]. Med Sci (Paris) 30, 1034-1039.

140. Guemez-Gamboa A, Coufal NG \& Gleeson JG (2014) Primary cilia in the developing and mature brain. Neuron $\mathbf{8 2}$, 511-521.

141. Mok CA, Heon E \& Zhen M (2010) Ciliary dysfunction and obesity. Clin Genet 77, 18-27.

142. Oh EC, Vasanth S \& Katsanis N (2015) Metabolic regulation and energy homeostasis through the primary Cilium. Cell Metab 21, 21-31.

143. Sen Gupta P, Prodromou NV \& Chapple JP (2009) Can faulty antennae increase adiposity? The link between cilia proteins and obesity. J Endocrinol 203, 327-336.

144. Marion V, Mockel A, De Melo C, et al. (2012) BBS-induced ciliary defect enhances adipogenesis, causing paradoxical higher-insulin sensitivity, glucose usage, and decreased inflammatory response. Cell Metab 16, 363-377.

145. Huang-Doran I \& Semple RK (2010) Knockdown of the Alstrom syndrome-associated gene Alms1 in 3T3-L1 preadipocytes impairs adipogenesis but has no effect on cellautonomous insulin action. Int J Obes (Lond) 34, 1554-1558.

146. Zhu D, Shi S, Wang H, et al. (2009) Growth arrest induces primary-cilium formation and sensitizes IGF-1-receptor signaling during differentiation induction of 3T3-L1 preadipocytes. J Cell Sci 122, 2760-2768. 
147. Marion V, Stoetzel C, Schlicht D, et al. (2009) Transient ciliogenesis involving Bardet-Biedl syndrome proteins is a fundamental characteristic of adipogenic differentiation. Proc Natl Acad Sci U S A 106, 1820-1825.

148. Dalbay MT, Thorpe SD, Connelly JT, et al. (2015) Adipogenic differentiation of hMSCs is mediated by recruitment of IGF-1r onto the primary cilium associated with cilia elongation. Stem Cells 33, 1952-1961.

149. Forcioli-Conti N, Lacas-Gervais S, Dani C, et al. (2015) The primary cilium undergoes dynamic size modifications during adipocyte differentiation of human adipose stem cells. Biochem Biophys Res Commun 458, 117-122.

150. North BJ, Marshall BL, Borra MT, et al. (2003) The human Sir2 ortholog, SIRT2, is an NAD+-dependent tubulin deacetylase. Mol Cell 11, 437-444.

151. Singla V \& Reiter JF (2006) The primary cilium as the cell's antenna: signaling at a sensory organelle. Science 313, 629-633.

152. Skurk T, Alberti-Huber C, Herder C, et al. (2007) Relationship between adipocyte size and adipokine expression and secretion. J Clin Endocrinol Metab 92, 1023-1033.

153. Marshall JD, Muller J, Collin GB, et al. (2015) Alstrom syndrome: mutation spectrum of ALMS1. Hum Mutat 36, 660-668.

154. Berisha SZ, Serre D, Schauer P, et al. (2011) Changes in whole blood gene expression in obese subjects with type 2 diabetes following bariatric surgery: a pilot study. PLOS ONE 6, e16729.

155. Vink R, Roumans NJ, Arkenbosch LA, et al. (2016) The effect of rate of weight loss on long-term weight regain in adults with overweight and obesity. Obesity 24, 321-327.

156. Rossmeislova L, Malisova L, Kracmerova J, et al. (2013) Weight loss improves the adipogenic capacity of human preadipocytes and modulates their secretory profile. Diabetes 62, 1990-1995.

157. Han YM, Kang GM, Byun K, et al. (2014) Leptin-promoted cilia assembly is critical for normal energy balance. J Clin Invest 124, 2193-2197.

158. Kang GM, Han YM, Ko HW, et al. (2015) Leptin elongates hypothalamic neuronal cilia via transcriptional regulation and actin destabilization. J Biol Chem 290, 18146-18155.

159. Rahmouni K, Fath MA, Seo S, et al. (2008) Leptin resistance contributes to obesity and hypertension in mouse models of Bardet-Biedl syndrome. J Clin Invest 118, 1458-1467.

160. Davenport JR, Watts AJ, Roper VC, et al. (2007) Disruption of intraflagellar transport in adult mice leads to obesity and slow-onset cystic kidney disease. Curr Biol 17, 1586-1594.

161. Seo S, Guo DF, Bugge K, et al. (2009) Requirement of BardetBiedl syndrome proteins for leptin receptor signaling. Hum Mol Genet 18, 1323-1331.

162. Berbari NF, Pasek RC, Malarkey EB, et al. (2013) Leptin resistance is a secondary consequence of the obesity in ciliopathy mutant mice. Proc Natl Acad Sci U S A 110, 7796-7801.

163. Loktev AV \& Jackson PK (2013) Neuropeptide Y family receptors traffic via the Bardet-Biedl syndrome pathway to signal in neuronal primary cilia. Cell Rep 5, 1316-1329.

164. Berbari NF, Lewis JS, Bishop GA, et al. (2008) Bardet-Biedl syndrome proteins are required for the localization of $G$ protein-coupled receptors to primary cilia. Proc Natl Acad Sci U S A 105, 4242-4246.

165. Stepanow S, Reichwald K, Huse K, et al. (2011) Allelespecific, age-dependent and BMI-associated DNA methylation of human MCHR1. PLOS ONE 6, e17711.

166. Heydet D, Chen LX, Larter CZ, et al. (2013) A truncating mutation of Alms1 reduces the number of hypothalamic neuronal cilia in obese mice. Dev Neurobiol 73, 1-13.
167. Braun JJ, Noblet V, Durand M, et al. (2014) Olfaction evaluation and correlation with brain atrophy in Bardet-Biedl syndrome. Clin Genet 86, 521-529.

168. Tadenev AL, Kulaga HM, May-Simera HL, et al. (2011) Loss of Bardet-Biedl syndrome protein-8 (BBS8) perturbs olfactory function, protein localization, and axon targeting. Proc Natl Acad Sci U S A 108, 10320-10325.

169. Nishimura DY, Fath M, Mullins RF, et al. (2004) Bbs2-null mice have neurosensory deficits, a defect in social dominance, and retinopathy associated with mislocalization of rhodopsin. Proc Natl Acad Sci US A 101, 16588-16593.

170. Ross AJ, May-Simera H, Eichers ER, et al. (2005) Disruption of Bardet-Biedl syndrome ciliary proteins perturbs planar cell polarity in vertebrates. Nat Genet 37, 1135-1140.

171. Lee MS, Hwang KS, Oh HW, et al. (2015) IFT46 plays an essential role in cilia development. Dev Biol 400, 248-257.

172. Lehman JM, Michaud EJ, Schoeb TR, et al. (2008) The Oak Ridge Polycystic Kidney mouse: modeling ciliopathies of mice and men. Dev Dyn 237, 1960-1971.

173. Lee J, Tucker RM, Tan SY, et al. (2015) Nutritional implications of taste and smell dysfunction. In Handbook of Olfaction and Gustation, pp. 829-864 [RL Doty, editor]. Hoboken, NJ: John Wiley and Sons Inc.

174. Aschenbrenner K, Hummel C, Teszmer K, et al. (2008) The influence of olfactory loss on dietary behaviors. Laryngoscope 118, 135-144.

175. Duffy VB, Backstrand JR \& Ferris AM (1995) Olfactory dysfunction and related nutritional risk in free-living, elderly women. J Am Diet Assoc 95, 879-884; quiz 885-876.

176. Dwyer ND, Adler CE, Crump JG, et al. (2001) Polarized dendritic transport and the AP-1 mul clathrin adaptor UNC-101 localize odorant receptors to olfactory cilia. Neuron 31, 277-287.

177. Stephan AB, Tobochnik S, Dibattista M, et al. (2012) The $\mathrm{Na}(+) / \mathrm{Ca}(2+)$ exchanger NCKX4 governs termination and adaptation of the mammalian olfactory response. Nat Neurosci 15, 131-137.

178. Antunes G, Sebastiao AM \& Simoes de Souza FM (2014) Mechanisms of regulation of olfactory transduction and adaptation in the olfactory cilium. PLOS ONE 9, e105531.

179. Choquette AC, Bouchard L, Drapeau V, et al. (2012) Association between olfactory receptor genes, eating behavior traits and adiposity: results from the Quebec Family Study. Physiol Behav 105, 772-776.

180. Jarick I, Vogel CI, Scherag S, et al. (2011) Novel common copy number variation for early onset extreme obesity on chromosome 11q11 identified by a genome-wide analysis. Hum Mol Genet 20, 840-852.

181. Tucker K, Overton JM \& Fadool DA (2012) Diet-induced obesity resistance of Kv1.3-/- mice is olfactory bulb dependent. J Neuroendocrinol 24, 1087-1095.

182. Hasegawa S, Hirabayashi T, Kondo T, et al. (2012) Constitutively expressed Protocadherin-alpha regulates the coalescence and elimination of homotypic olfactory axons through its cytoplasmic region. Front Mol Neurosci 5, 97.

183. Lushchak OV, Carlsson MA \& Nassel DR (2015) Food odors trigger an endocrine response that affects food ingestion and metabolism. Cell Mol Life Sci 72, 3143-3155.

184. Palouzier-Paulignan B, Lacroix MC, Aime P, et al. (2012) Olfaction under metabolic influences. Chem Senses 37, 769-797.

185. Stafford LD \& Whittle A (2015) Obese individuals have higher preference and sensitivity to odor of chocolate. Chem Senses 40, 279-284.

186. Patel BP, Aschenbrenner K, Shamah D, et al. (2015) Greater perceived ability to form vivid mental images in individuals with high compared to low BMI. Appetite 91, 185-189. 
187. Seo S, Mullins RF, Dumitrescu AV, et al. (2013) Subretinal gene therapy of mice with Bardet-Biedl syndrome type 1 . Invest Ophthalmol Vis Sci 54, 6118-6132.

188. Alinejad B, Shafiee-Nick R, Sadeghian H, et al. (2015) Metabolic effects of newly synthesized phosphodiesterase-3 inhibitor 6-[4-(4-methylpiperidin-1-yl)-4-oxobutoxy]-4-methylquinolin2(1H)-one on rat adipocytes. Daru 23, 19.

189. Sahu M, Anamthathmakula P \& Sahu A (2015) Phosphodiesterase-3B-cAMP pathway of leptin signalling in the hypothalamus is impaired during the development of diet-induced obesity in FVB/N mice. J Neuroendocrinol $\mathbf{2 7}$, 293-302.

190. Rahimi R, Ghiasi S, Azimi H, et al. (2010) A review of the herbal phosphodiesterase inhibitors; future perspective of new drugs. Cytokine 49, 123-129.

191. Pendleton M, Brown S, Thomas CM, et al. (2013) Potential toxicity of caffeine when used as a dietary supplement for weight loss. J Diet Suppl 10, 1-5. 